\title{
EN TORNO AL ARTÍCULO 14 DE LA CEDH: CONCEPTO, JURISPRUDENCIA Y NUEVOS DESAFIOS DE (Y ANTE) EL CONSEJO DE EUROPA.
}

\author{
Juana María Gil Ruiz
}

\begin{abstract}
Resumen
El Consejo Europeo es consciente de que "la realización de iure y de facto de la igualdad entre mujeres y hombres es un elemento clave de la prevención de la violencia contra la mujer". Este reconocimiento obliga a revisar el Derecho antidiscriminatorio clásico, basado en la yuxtaposición de los factores de discriminación -sexo, raza, color, lengua, religión, opiniones políticas u otras, origen nacional o social ... - y partir de la naturaleza estructural de la subordinación de las mujeres como ciudadanas bajo un enfoque prioritario del gender mainstreaming. En este trabajo se analizará la evolución de determinados documentos europeos (el CEDH y la Carta Social Europea) así como el recientemente firmado Convenio de Estambul, dentro del nuevo marco de derecho antisubordiscriminación asumido por Europa, sin olvidarnos las Convenciones y Conferencias internacionales más relevantes sobre su desarrollo.
\end{abstract}

Palabras clave: Derecho antidiscriminatorio, igualdad, discriminación, gender mainstreaming, Consejo de Europa

\section{INTRODUCCIÓN Y JUSTIFICACIÓN METODOLÓGICA.}

El artículo 14 de la Convención Europea de Derechos Humanos (CEDH) no enuncia una prohibición independiente relativa a la discriminación, sino que sólo la proscribe vinculada al goce de los derechos y libertades recogidos y definidos en la Convención. La necesidad, pues, de garantías específicas adicionales llevó a la conveniencia de firmar un Protocolo específico en el ámbito de la Igualdad y la no discriminación, auspiciado tanto por la Asamblea Parlamentaria como por los comités de personas expertas intergubernamentales competentes del Consejo de Europa. Será en 1990 cuando en el 70 Coloquio Internacional sobre el Convenio Europeo de derechos Humanos reconozca la paradoja de que siendo los principios de igualdad y de no discriminación elementos esenciales del derecho internacional en materia de derechos humanos, sin embargo apenas poseyeran expansión jurisprudencial, y en consecuencia, garantías de protección. Se trataba, pues, de dotarlos de un cierto carácter sustancial y ello se cerró con la aprobación del Protocolo no 12 que entró en vigor de

\footnotetext{
${ }^{1}$ Catedrática de Filosofía del Derecho, desarrollando su actividad en la Universidad de Granada. Asesora del Instituto Andaluz de la Mujer y Vocal del Observatorio Andaluz de Violencia de Género. Miembro del Comité Permanente de Análisis y Estudio de la Violencia contra las mujeres que se ha creado desde la Dirección General de Violencia de Género y Asistencia a Víctimas. Editora de la revista jurídica Anales de la Cátedra Francisco Suárez y pertenece al Consejo Asesor de la Revista Ius Novum y al Comité Científico de la Revista de la Facultad de Derecho de la Universidad de Granada. E-mail: jgil@ugr.es
} 
forma general el 1 de abril de 2005, y en particular en España el 1 de junio de 2008. En este sentido, los Estados miembros del Consejo de Europa, tal y como reza en el preámbulo, tienen claro y en cuenta el principio fundamental de la igualdad, resuelven tomar nuevas medidas para promoverla, y reiteran la libertad de los Estados para promocionarla de manera plena y efectiva, siempre que respondan a una justificación objetiva y razonable.

En paralelo, la Carta Social Europea se trata de un Tratado Internacional elaborado por el Consejo de Europa, concerniente a los problemas sociales, aunque siempre centrada en el ámbito socio-laboral. En este sentido, hace especial referencia a los "niños y adolescentes", derechos de las personas físicas o mentalmente disminuidas a formación profesional o a su readaptación profesional, trabajadores emigrantes, mujeres y madres trabajadoras. Sin embargo, se echa de menos en la Carta Social el enfoque de género y su centralización en la protección socio-laboral lo que viene a dejar fuera a muchísima ciudadanía, mujeres -madres o no- que trabajan, aunque no en la esfera pública, con lo que no poseen ese reconocimiento ni protección de sus derechos. Esto significa que el sesgo de género reatraviesa todos los derechos sociales-laborales mencionados a los largo del texto de la Carta Social Europea, aunque la estructura de sexo-género no se mencione (a excepción de la protección especial del art. 8) y más aún sumados otros sistemas excluyentes como raza, color, discapacidad, edad, entre otros.

Pese a estas deficiencias de enfoque y sus consecuentes limitaciones prestacionales, el Comité Europeo de Derechos Sociales ha llamado la atención al Estado español por incumplimiento de su legislación interna con respecto a los preceptos reconocidos en la Carta Social Europea. Hemos incorporado en este trabajo el pronunciamiento condenatorio último del Comité Europeo, y le hemos sumado la lectura de género que se entreteje de sus siete conclusiones de no conformidad. Y es que además, el Comité Europeo de Derechos Sociales desecha el consabido argumento de la crisis como justificativo de restricciones legales en derechos sociales incluidos en la Carta Social Europea y que, por el contrario, deben ser especialmente garantizados en estos momentos.

De cualquier modo, y pese a la deficiente regulación de la Carta Social Europea centrada, insistimos, en lo socio-laboral, no debe desconocerse el Protocolo Adicional ratificado por España en Estrasburgo el 5 de mayo de 1988, y publicado en el BOE en abril de 2000. En su lectura comienza a detectarse una incipiente preocupación por la igualdad de oportunidades y de trato en materia de empleo y de profesión sin discriminaciones por razón de sexo, como objetivo de su política, vinculación de las partes, compromisos, supervisión de la observancia de éstos y, finalmente, su aplicación.

No obstante, tanto el Convenio Europeo para la Protección de los Derechos Humanos y de las Libertades Fundamentales, como la Carta Social Europea, hacen referencia en sus Preámbulos y en la Jurisprudencia del TEDH en torno al art. 14, a los Tratados internacionales vinculantes adoptados por los Estados. Ello obliga a acercarse a éstos y a la consecuente evolución del principio de no discriminación, originario 
de un nuevo marco de Derecho Antidiscriminatorio, que reconfigura el concepto de igualdad basado en un nuevo modelo de ciudadanía, esta vez sí inclusivo de todos los seres humanos en su diversidad. En definitiva, la adopción de estos Tratados Internacionales, la incorporación del concepto de discriminación reconocido en éstos documentos (CEDAW 1979, III Conferencia Mundial de la Mujer de Nairobi 1985, II Conferencia de Viena 1993 ... ) y el compromiso con el gender mainstreaming (IV Conferencia Mundial sobre la Mujer de Beijing 1995, Tratado de Ámsterdam, Tratado de Lisboa ... ) ratificado por casi todos los países del globo terráqueo, obliga a superar los esquemas conceptuales del Derecho liberal, incluido el Derecho antidiscriminatorio clásico, dando cabida al sistema sexo-género en el Derecho y en la cultura jurídica de forma prioritaria y transversal, para así poder reconfigurar el principio de igualdad y el modelo de ciudadanía que lo sustenta. No en vano, los Gobiernos y las Naciones Unidas elevan el pleno disfrute de los derechos de las mujeres a prioridady conminan a que la igualdad de las mujeres y sus derechos se integren en las principales actividades de todo el sistema de Naciones Unidas (II Conferencia Mundial para la Protección de los derechos humanos, Viena, junio 1993).

Sin duda este compromiso responde a que en el diseño, gestación y aplicación de todas las medidas jurídicas y políticas haya que tener en cuenta las preocupaciones, las necesidades y aspiraciones de las mujeres como ciudadanas-, en la misma medida que las de los hombres -como ciudadanos-, reatravesadas, sin duda, por cortes sistémicos que penetran en el factor sexo-género. Hablamos de color, religión, edad, ubicación geográfica, discapacidad, orientación sexual... La violencia de género es, el extremo más dramático de esta discriminación, o mejor dicho, es la discriminación en sí misma, entendiendo este último concepto desde la perspectiva del sistema sexo-género (que subordina a las mujeres) y no desde la bilateralidad o neutralidad de los sexos, ni tampoco reducido a lo laboral, como única parcela de lo social. En este sentido, y habida cuenta de que los documentos europeos aquí analizados se habían quedado muy cortos en la definición y protección de la discriminación, centrada en la enumeración no jerárquica de factores o sistemas de exclusión, y en todo caso, centrada en lo laboral, los Estados miembros del Consejo de Europa y demás signatarios firmaron recientemente el Convenio del Consejo de Europa sobre Prevención y Lucha contra la Violencia contra la Mujer y la Violencia Doméstica, hecho en Estambul, el 11 de mayo de 2011.

Tal y como referimos al final de este trabajo, sólo desde aquí será identificable y abordable violencias donde la estructura de género impera y es reatravesada por (edad, raza, religión, estado civil, ubicación geográfica ... ) tales como los matrimonios forzosos de niñas pequeñas, el drama de las niñas viudas, la violencia hacia las niñas por la dote, el incesto, el infanticidio, el planchado de los senos, las restricciones dietéticas en las niñas, el alargamiento de cuello, la ablación del clítoris, crímenes de honor, la inmolación de la viuda, el femicidio ... o el generocidio, discriminaciones por el solo hecho, de haber nacido mujeres. 


\section{PUNTO DE PARTIDA NORMATIVO.}

Iniciamos nuestro análisis con el enunciado del artículo 14 del Convenio Europeo para la protección de los derechos humanos y de las libertades fundamentales, de 4 de noviembre de 1950, ratificado por España el 26 de septiembre de 1979:

Artículo 14. Prohibición de discriminación.

El goce de los derechos y libertades reconocidos en el presente Convenio ha de ser asegurado sin distinción alguna, especialmente por razones de sexo, raza, color, lengua, religión, opiniones políticas u otras, origen nacional o social, pertenencia a una minoría nacional, fortuna, nacimiento o cualquier otra situación.

Asimismo, este artículo del Convenio está claramente vinculado con el Protocolo no 12 al mismo (STE $n^{\circ}$ 177), elaborado en el Consejo de Europa por el Comité Director de Derechos Humanos (CCDH), adoptado por el Comité de Ministros el 26 de junio de 2000 y abierto a la firma de los Estados Miembros del Consejo de Europa el 4 de noviembre de 2000. De hecho, el artículo 1 del Protocolo abarca la protección ofrecida por el artículo 14 del Convenio, pero su alcance es más amplio. Dice así:

Artículo 1. Prohibición general de la discriminación.

El goce de todos los derechos reconocidos por la ley han de ser asegurados sin discriminación alguna, en particular por razones de sexo, raza, color, lengua, religión, opiniones políticas o de otro carácter, origen nacional o social, pertenencia a una minoría nacional, fortuna, nacimiento o cualquier otra situación.

Nadie podrá ser objeto de discriminación por parte de cualquier autoridad pública, basada en particular en los motivos mencionados en el apartado 1.

Como Protocolo adicional, no modifica ni suprime el artículo 14 del Convenio, pero la cláusula general de no discriminación recogida en el artículo 1, va más allá del "goce de los derechos humanos y libertades reconocidos en el (presente) Convenio". Y ello es debido a que la protección ofrecida por el artículo 14 de la Convención, en lo que se refiere a la igualdad y a la no discriminación, es limitada con respecto a lo que se prevé en las disposiciones de otros instrumentos internacionales, como analizaremos más adelante. Esto implica también cierta libertad para los sistemas jurídicos nacionales, aun sometidos necesariamente a las obligaciones que hubieren adquirido por los Convenios y Tratados Internacionales firmados. A saber: la Convención sobre la eliminación de todas las formas de discriminación contra la mujer (CEDAW, 1979) o el Convenio sobre la eliminación de todas las formas de discriminación racial, entre otros.

Efectivamente el contenido del artículo 14 de la Declaración Europea de Derechos Humanos arriba referido no enuncia una prohibición independiente relativa a la discriminación, sino que sólo la proscribe vinculada al goce de los derechos y libertades recogidos y definidos en la Convención. Eran pues necesa rias ciertas garantías específicas adicionales, como ya sucediera en 1950 con el artículo 5 del Protocolo nº al Convenio Europeo de derechos humanos, en lo referente a la igualdad entre cónyuges. Por esta razón, los Estados miembros del Consejo de Europa firmaron el Protocolo no 12 partiendo del principio fundamental de igualdad de todas las 
personas ante la ley, su derecho a igual amparo, y resueltos a tomar nuevas medidas para promover la igualdad de todos mediante la garantía colectiva de una prohibición general de discriminación mediante el Convenio. No obstante, este principio de no discriminación no impide a los Estados Partes -especifica el Protocolo- a tomar medidas para promover una igualdad plena y efectiva, siempre que respondan a una justificación objetiva y razonable.

\section{LA NECESIDAD DEL PROTOCOLO No 12.}

Será a partir de los años 60 y muy especialmente en las sucesivas décadas, cuando se plantee la necesidad de un Protocolo específico en el ámbito de la igualdad y de la no discriminación, tanto por la Asamblea Parlamentaria como por los comités de personas expertas intergubernamentales competentes del Consejo de Europa. En 1990, en el 70 Coloquio Internacional sobre el Convenio Europeo de Derechos Humanos (Copenhague, Oslo y Lund, 30 de mayo-2 de junio de 1990), los participantes reconocen la paradoja de que siendo los principios de igualdad y de no discriminación elementos esenciales del derecho internacional en materia de derechos humanos, sin embargo apenas poseyeran expansión jurisprudencial (y en consecuencias, garantías de protección), al ostentar el artículo 14 un carácter mera y netamente accesorio que no sustancial.

En este sentido, dos grupos de trabajo comenzaron a impulsar estudios al respecto. Uno de ellos estaba encabezado por el Comité Director para la Igualdad entre Hombres y Mujeres (CDEG); y el segundo por la Comisión Europea contra el Racismo y la Intolerancia (ERCI). Sin duda, esta bipartición inicial en las propuestas, condicionaría el resultado final de la medida adoptada por el Consejo Europeo.

El primero de estos grupos (CDEG) subrayó la ausencia, en el marco de los instrumentos vinculantes del Consejo de Europa, de protección jurídica de la igualdad entre hombres y mujeres como derecho fundamental independiente. No dudó pues, en plantear, la necesidad de incluir, en el marco del Convenio Europeo de derechos humanos, una norma jurídica que recogiera, sin lugar a dudas, un derecho fundamental independiente de la mujer y del hombre a la igualdad. Y esto es así, habida cuenta de que una norma jurídica a estos efectos constituía una de las condiciones esenciales para alcanzar la igualdad de iure y de facto de la ciudadanía. Los trabajos de este grupo desembocaron en la propuesta circunstancial de introducir ese derecho en un Protocolo. El Comité de Ministros en 1996 trasladó la propuesta para un estudio por parte del Comité Director de Derechos Humanos quien, tras los oportunos trabajos de su Comité de Expertos para el Desarrollo de los Derechos Humanos, convino en octubre de ese mismo año, que era necesario que el Consejo de Europa adoptase normas en el ámbito de la igualdad entre mujeres y hombres, aunque situándose en el plano del principio de la universalidad de los derechos humanos, que no en un enfoque sectorial. En este sentido, y haciendo suyo el informe, el Consejo de Ministros, en diciembre de 1996, encargó, al propio Comité Director de Derechos Humanos que estudiase soluciones de tipo 
normativo acerca de la igualdad entre mujeres y hombres, distintas del proyecto de protocolo específico al Convenio Europeo de Derechos Humanos.

El segundo de los grupos se centró en la lucha del racismo y la intolerancia, en buena medida auspiciados por la primera Cumbre de Jefes de Estado y de Gobierno de los Estados miembros celebrada en Viena los días 8 y 9 de octubre de 1993. La Declaración y el Plan de Acción sobre la lucha contra el racismo, la xenofobia, el antisemitismo y la intolerancia adoptados en esa ocasión eran un buen reflejo del grado de preocupación por el resurgimiento de un cierto clima de intolerancia. Fruto de ello, los Jefes de Estado y de Gobierno decidieron crear la Comisión Europea contra el Racismo y la Intolerancia, con dos objetivos claros: el primero, el de reforzar las garantías contra toda forma de discriminación; y el segundo -dirigido a conseguirlo- el estudio de los instrumentos jurídicos internacionales aplicables en la materia para reforzarlo.

Finalmente la Comisión Europea contra el Racismo y la Intolerancia (ECRI) transmitió sus conclusiones al Comité de Ministros inclinándose por un protocolo adicional que contuviese una cláusula general de protección contra la discriminación por razones de raza, color, lengua, religión u origen étnico o nacional. Nótese cómo no se aludía a la razón de sexo, probablemente porque se partía de la idea fundamental defendida por el Comité Director para la Igualdad entre Hombres y Mujeres, antes referida: la necesidad de adopción de normas en el ámbito de la igualdad entre mujeres y hombres, aunque situándose en el plano del principio de la universalidad de los derechos humanos, en tanto que ciudadanía, que no colectivo.

De cualquier modo, la ECRI reconocía la importancia del Derecho a favor de la justicia racial, pero a su vez, la insuficiencia del mismo para poder eliminar el racismo en sus múltiples formas con respecto a distintos grupos. No obstante, recomendaba la conveniencia de consagrar al derecho a la protección contra la discriminación racial como derecho fundamental del ser humano, a la vez que alertaba en torno al resurgimiento de las ideologías racistas y de las intolerancias religiosas.

El Comité de Ministros decidió en abril de 1996, tras el informe de la ECRI, elevarlo al Comité Director para los Derechos Humanos para que se manifestara en torno a la oportunidad y/o viabilidad de un instrumento jurídico contra el racismo y la intolerancia, reforzando la cláusula de no discriminación del Convenio Europeo.

Tras los informes de ambos grupos y las distintas propuestas arbitradas que oscilaban desde un protocolo adicional, basado en la propuesta de la ECRI, un protocolo adicional que ampliase de manera general el ámbito de aplicación del art. 14, una recomendación del Comité de Ministros e incluso un acuerdo-marco u otro convenio, el Comité Director para los Derechos Humanos en octubre de 1997, optó por una medida ecléctica, es decir, un solo Protocolo que reuniera tanto medidas para garantizar la igualdad entre mujeres y hombres, como las relativas al racismo y a la intolerancia.

El Comité de Ministros, no tardó en reunirse, y el 10 y 11 de marzo de 1998, en su 622a reunión de 
Delegados de los Ministros encomendó la redacción del Protocolo Adicional (que ahora nos ocupa, n¹2) al Convenio de Derechos Humanos, ampliando de manera general el ámbito de aplicación de su artículo 14 y contuviese una lista abierta -no exhaustiva- de motivos de discriminación. Durante los años 1998 y 1999, el Comité Director de los Derechos Humanos, en conjunción con su Comité de Expertos y la colaboración de los representantes de los dos grupos arriba señalados, el CDEG y el ECRI trabajaron para responder a esta demanda. Finalmente, durante el Coloquio Europeo Regional organizado por el Consejo de Europa y celebrado con motivo del 50 aniversario de la Declaración Universal de los Derechos Humanos, en Estrasburgo, los días 2 a 4 de septiembre de 1998, los participantes se expresaron a favor de una conclusión rápida de la redacción del proyecto de protocolo.

El Comité Director de los Derechos Humanos, en su reunión extraordinaria de 9 y 10 de marzo de 2000 y tras consultar al Tribunal Europeo de Derechos Humanos, a la Asamblea Parlamentaria y a otras instancias del Consejo de Europa, ultimó el texto del Protocolo que de manera inmediata transmitió al Comité de Ministros, cumpliendo pues con la petición cursada por éste en 1998. El texto fue adoptado el 26 de junio de 2000, en la $715^{\mathrm{a}}$ reunión de Delegados de los Ministros, y se abrió a la firma por los Estados miembros del Consejo de Europa el 4 de noviembre de 2000. El instrumento de Ratificación de este Protocolo se ha publicado en el BOE nº 64, de 14 de marzo de 2008 (pp. 15299-15304). Este Protocolo, pues, completará al Convenio de Derechos Humanos y de las Libertades Fundamentales, entrando en vigor de forma general el 1 de abril de 2005, y en particular en España el 1 de junio de 2008, tal y como establece el artículo 5.

\section{LA JURISPRUDENCIA DEL TEDH EN TORNO A LA DISCRIMINACIÓN.}

Los Estados miembros del Consejo de Europa en el Preámbulo del Protocolo no 12 tienen claro y en cuenta el principio fundamental de la igualdad, resuelven tomar nuevas medidas para promoverla, y reiteran la libertad de los Estados para promocionarla de manera plena y efectiva, siempre que respondan a una justificación objetiva y razonable.

Tal y como hemos visto en el capítulo 1, donde se recoge la lista de motivos que figura en el art. 1 del Protocolo no 12 (idéntica a la del art. 14 del Convenio Europeo de Derechos Humanos), se opta por una fórmula abierta, no exhaustiva, en vez de mencionar de manera casuística las múltiples formas de discriminación que puede padecer un ser humano. No en vano se echan de menos, entre otras razones discriminatorias, la discapacidad física y/o psíquica, la orientación sexual o la edad. No obstante, la jurisprudencia del TEDH ya ha aplicado el art. 14 del Convenio a motivos de discriminación no mencionados, como es la orientación sexual. (Sentencia de 21 de diciembre de 1999 sobre el asunto Salgueiro da Silva Mouta v. Portugal).

La jurisprudencia del TEDH en torno a la discriminación ha sido muy constante. Bien es verdad que 
parte de esa estructura estable se debe al exceso de citas de sus propios pronunciamientos con lo que el avance en esta materia se hace difícil. No obstante, dependiendo del tipo de derecho que se encuentre en riesgo, por discriminación, el TEDH ha optado por ser más atrevido en el lenguaje o bien, en casos donde entraba en juego alguna cuestión socio-económica, más cauto y vago con el lenguaje. En este último extremo podemos situar las demandas por razones de raza, etnia y sexo, donde se ha valorado el uso de un concepto de discriminación formalista y una interpretación de la igualdad de género simplista y paternalista (Besson, 2008), permaneciendo insensible en casos de múltiple discriminación (Radacic, 2008), aunque se detecta una incipiente preocupación por la violencia contra las mujeres como discriminación.

Asimismo, ha reparado terminológicamente en la Sentencia 23 de julio de 1968, Serie A, no 6, apartado 10, sobre el asunto de la lingüística belga, en el ligero matiz del lenguaje incorporado en la versión francesa del art. 1 del Protocolo no 12 (sans discrimination aucune) frente a la del art. 14 del CEDH (sans distinction aucune) que no implica, en ningún caso, un significado diferente sino una adecuación terminológica para ilustrar mejor el concepto de discriminación en el sentido del art. 14 del CEDH.

Ha destacado que no todas las distinciones o diferencias de tratamiento equivalían a una discriminación y que "una distinción es discriminatoria si "carece de justificación objetiva y razonable", es decir si no persigue un "objetivo legítimo" o si no existe "relación razonable de proporcionalidad entre los medios empleados y el objetivo perseguido" (Sentencia de 28 de mayo de 1985, Serie A, no 94, apartado 72, relativa al asunto Abdulaiz, Cabales y Balkandali v. el Reino Unido). Sin embargo, en la medida en que no toda distinción o diferencia de trato equivale a discriminación, y debido al carácter general del principio de no discriminación, -no incluyéndose una cláusula restrictiva en el Protocolo-, el TEDH da cierto margen a los Estados para que puedan determinar si las diferencias entre situaciones a otros efectos análogos justifican distinciones de trato y en qué medida. Las situaciones en las que esas distinciones son "perfectamente aceptables" están suficientemente salvarguardadas por el propio significado de "discriminación". Este es el caso por ejemplo de distinciones en atención a la nacionalidad, que da derecho a prestaciones (Sentencia de 28 de diciembre de 1984, sobre el asunto Rasmussen v. Dinamarca, Serie A, no 87); o medidas de elaboración y aplicación de política fiscal (Sentencia de 3 de octubre de 1997, en torno al asunto National and Provincial Building Society y otros v. el Reino Unido, compendio de sentencias y resoluciones 1997-VII, apartado 8). Las razones de tipo socio-económico que las envuelve se vislumbran en las decisiones adoptadas.

Sin embargo, recientemente hemos detectado una mayor sensibilidad con respecto a la igualdad de mujeres y hombres; raza, color o etnia y a las terribles consecuencias de su discriminación. "Cuando la diferencia de trato está basada en raza, color o etnia, la noción de justificación razonable y objetiva debe interpretarse de la forma más estricta posible" ( Caso Larkos v, Chipre, n²9515/95, párrafo 196). El propio TEDH lo deja aún más 
claro cuando afirma -en lo que al margen de apreciación estatal se refiere- que "tiene que alegarse razones de mucho peso para que una diferencia de trato basada en el sexo pueda ser considerada compatible con el Convenio" (Sentencia, asunto Ünal Tekeli v. Turquía. Párrafo 53); y se apoya en el consenso europeo para poder establecer estándares comunes europeos sobre determinadas materias. En este sentido, el TEDH suele resolver después de observar el Derecho comparado en otros Estados del Consejo de Europa, considerando que el Convenio es un instrumento vivo que puede ser interpretado a "la luz de las condiciones actuales" (Sentencia de 25 de abril de 1978, Caso Tyrer v. Reino Unido, demanda 5856/72, párrafo 31).

En el caso Ünal Tekeli v. Turquía, arriba mencionado, el TEDH se basó en el consenso europeo al apreciar que Turquía era el único país en Europa que prohibía a las mujeres casadas la conservación de sus apellidos En este sentido, "Los Estados parte disfrutan de un cierto margen de apreciación para valorar si, y hasta qué punto, las diferencias justifican un tratamiento diferente por parte de las leyes. El alcance del margen de apreciación variará de acuerdo a las circunstancias, la materia objeto de estudio y sus antecedentes (ver Caso Rasmussen v. Dinamarca, sentencia de 28 de noviembre de 1984, Serie A no 87, \& 40, e Inze v. Austria, sentencia del 28 de octubre de 1987, Serie A no 126 \& 41" (párrafo 52).

También se ha pronunciado sobre la orientación sexual, buscando no tanto una legislación unificada como ciertos puntos de convergencia europeos. En este sentido "la Comisión ha referido una clara tendencia en los Estados Miembros al reconocimiento legal de las reasignaciones de género. Consideró que, en el caso de una persona transexual que se había sometido a una operación de reasignación de género en un Estado Miembro y que vivía en él formando una familia, debía haber una presunción a favor del reconocimiento legal de esa relación y que la negación de dicho reconocimiento requeriría una justificación especial" (Sentencia de 22 de abril de 1997, demandas 75/1995/581/667, Caso X, Y Y Xv. Reino Unido, párrafo 40)

La sensibilidad con respecto a la igualdad de género se va detectando desde que en 1985 el TEDH dictaminara que el avance en la igualdad entre los sexos era un objetivo muy importante para los Estados Miembros del Consejo de Europa (Abdulaziz y otros v. Reino Unido) y un principio clave subyacente en el Convenio Europeo de Derechos Humanos (Sahin v. Turquía). Todas estas circunstancias justifican sobremanera el que debamos dedicar un próximo epígrafe (vid. capítulo 6) a tratar esta evolución de la discriminación, basada en los instrumentos internacionales más relevantes y en su recepción europea y nacional, lo que ha supuesto un nuevo marco de Derecho antidiscriminatorio.

En lo que a la discriminación indirecta se refiere, habrá que esperar a 2007, en Sentencia de 13 de noviembre de 2007, no 57325/00, relativa al asunto D.H. y otras v. República Checa, para que el Tribunal se pronunciara con claridad sobre las leyes que parecen neutras pero que pueden ocasionar un efecto discriminatorio. En este sentido, y refiriéndose a un anterior pronunciamiento -Sentencia de 6 de enero de 2005, 
n 58461/00, sobre asunto Hoogendik v. Países Bajos- alega el TEDH:

"Cuando un demandante puede demostrar, basándose en estadísticas oficiales, la existencia de un indicio de que una regla especifica, a primera vista $-y$ a pesar de que esté formulada de una manera neutra - afecta a un porcentaje claramente más alto de mujeres que de hombres, es obligación del Gobierno demandado demostrar que esta diferencia es el resultado de factores objetivos que no están basados en discriminación por razón de sexo. Si la obligación de demostrar que el impacto diferencial sobre hombres y mujeres no es en práctica discriminatorio no recayera en el gobierno demandado, sería en la práctica extremadamente difícil para los demandantes probar la existencia de discriminación indirecta" (Sentencia de 6 de enero de 2005, nº 58461700, Asunto Hoogendijk v. Países Bajos).

No en vano, el TEDH recomienda la inversión de la carga de la prueba apostando por un concepto de igualdad sustantivo y material (de actuación positiva) que no sólo formal. "(L)os procedimientos del Convenio no siempre se prestan a aplicaciones rigurosas del principio affirmanti incumbit probatio (quien alega algo debe probarlo Aktaş v. Turquía (extractos), no 24351/94, \$272, TEDH 2003-V). En algunas circunstancias, cuando los hechos permanecen, totalmente o en gran medida, bajo el sólo conocimiento de las autoridades debe considerarse que la carga de la prueba recae sobre las autoridades, que deben proporcionar una explicación convincente y satisfactoria (ver Salman c. Turquía [GC], n² 21986/93, \$ 100, TEDH 2000-VII; y Anguelova c. Bulgaria, no 38361/97, \$ 111, TEDH 2002-IV; D.H. y otras v. República Checa [GC], n 57325/00, 13 Noviembre 2007, párrafo 179). De hecho, en algunas circunstancias, -insiste el TEDH- "el no tomar medidas de tratamiento diferencial para intentar corregir desigualdades puede ocasionar una violación del art. 14" (párrafo 175).

No obstante, justo es señalar que el carácter global (no programático) del Convenio no es la intervención, ni tampoco impone ninguna obligación de adoptar medidas de acción positiva por los Estados, pues se debe a la garantía colectiva de los derechos individuales establecidos. Esta cuestión sobre la implicación de obligaciones positivas puede plantearse en caso de que exista un vacío manifiesto en la protección ofrecida por el Derecho nacional contra la discriminación que afectaría gravemente en las relaciones entre particulares, lo que señalaría claramente la responsabilidad del Estado y la puesta en jaque del art. 1 del Protocolo. (v. mutatis mutandi, Sentencia del Tribunal de 26 de marzo de 1985 sobre el asunto X e Yv. los Países Bajos, Serie A, no 91, apartados 23, 24, 27 y 30). Este sería el caso de denegación arbitraria del acceso a un trabajo, acceso a restaurantes, o a servicios que puedan disponer los particulares a disposición del público, entre otros. Pero el alcance de la protección adicional, se recoge claramente para los casos en que una persona sea objeto de discriminación, en el art. 1 del Convenio, garantizando la protección contra la discriminación por parte de las autoridades públicas, que no las relaciones entre particulares. Ni el Convenio, ni el Protocolo constituyen un elemento apropiado para definir los elementos de una obligación tan amplia; pero ninguno de los dos obstaculiza, sino todo lo contrario, la apuesta por la igualdad efectiva de las legislaciones nacionales, vinculadas a los Tratados Internacionales y a la apuesta europea seria por la consecución de la igualdad efectiva de su ciudadanía. "Ninguna de las disposiciones 
del presente Convenio será interpretada en el sentido de limitar o perjudicar aquellos derechos humanos y libertades fundamentales que podrían ser reconocidos conforma a las leyes de cualquier Alta Parte Contratante o en cualquier otro Convenio en el que ésta sea parte" (Art. 3 del Protocolo 12). El término "ley", pues, abrazado en el art. 1 del CEDH en su propia redacción, no puede llevarnos a duda; a saber: "El goce de todos los derechos reconocidos por la ley han de ser asegurados sin discriminación alguna, en particular por razones de sexo, raza, color, religión, opiniones políticas o de otro carácter, origen nacional o social, pertenencia a una minoría nacional, fortuna, nacimiento o cualquier otra situación". Ésta puede abarcar igualmente el Derecho Internacional, pero eso no significa que esa disposición confiera al TEDH competencia para examinar el respeto de las reglas de derecho contenidas en otros instrumentos internacionales.

Esto último sin duda conectaría con la reciente, pero importante, preocupación del TEDH en supuestos de violencia de género como discriminación, lo que posteriormente impulsaría la aprobación del reciente Convenio de Estambul por el Consejo de Europa sobre Prevención y Lucha contra la Violencia contra la Mujer y la Violencia Doméstica, hecho en Estambul en 2011, en la línea de protección establecida por los Tratados Internacionales vinculantes y el Derecho Europeo. Recogiendo la CEDAW de 1979 (Convención sobre eliminación de todas las formas de discriminación contra la mujer, aprobada por la Asamblea Nacional de Naciones Unidas) y la Convención Interamericana para prevenir, sancionar y erradicar la violencia contra la mujer, de 9 de junio de 1994 (Convención de Belém do Pará, adoptada por la Asamblea General de Estados Americanos), la jurisprudencia del TEDH y posteriormente en 2011, el Consejo de Europa en Estambul, darán un paso hacia adelante en la erradicación de la discriminación contra las mujeres.

La Sentencia de 4 de marzo de 2004, demanda 39272/98, del caso M.C. v. Bulgaria, examina una violación múltiple de una joven de 14 años por parte de dos varones a los que conocía y con los que salió voluntariamente a condición de volver a casa a una hora determinada. La agredida denunció, pero sorprendentemente las autoridades búlgaras no imputaron a los dos demandados por falta de pruebas sobre si hubo resistencia física a la violación, o de que ambos hubieran utilizado fuerza física o coacciones contra ella. En Bulgaria, en la práctica judicial, una falta de resistencia física puede ser considerada como prueba de consentimiento.

El TEDH examinó la legislación búlgara en tanto que su Código Penal limitaba la definición de violación contra la mujer al supuesto en que ésta es obligada a una relación sexual "a través del uso de la fuerza o de amenazas", lo que abandonaba a su suerte a las mujeres, con mayor riesgo de sufrir violencia. El Tribunal dictaminó que la definición de violación de la legislación búlgara vulneraba los art. 3 y 8 del Convenio, apostando por una intervención positiva del Estado (y no omisiva) en tanto firmante del mismo, ya que "requieren la criminalización y la persecución efectiva de todos los actos sexuales perpetrados sin consentimiento, incluso en 
ausencia de resistencia física de la víctima”.

En esta misma línea de compromiso por la igualdad de género y la erradicación de la violencia como discriminación, encontramos el caso Opuz v. Turquía, donde el TEDH "considera que la violencia sufrida por la demandante y por su madre debe considerarse violencia de género, que es una forma de discriminación contra las mujeres" (Sentencia de 9 de junio de 2009, demanda 33401/02, párrafo 200, caso Opuz v. Turquía). Asimismo, reiteró la obligación positiva de los Estados de combatir y erradicar la violencia contra las mujeres a través de investigaciones efectivas y de juzgar a los culpables, incluso cuando la violencia es perpetrada por actores no estatales. La omisión, en estos casos, es de una grave irresponsabilidad estatal y ello implicaba no sólo la vulneración del derecho de no discriminación por parte del Estado turco sino un atentado al derecho a la vida de la madre por falta de diligencia debida, y una violación del art. 3 de la Convención contra la tortura y otros tratos o penas crueles, inhumanos o degradantes. En esta misma línea se pronunció en el asunto A.T. v Hungría (Ver Comunicación del Comité contra la Discriminación de la Mujer no 2/2003, dictamen del 26/01/2005), y consideró que la ausencia de medidas adecuadas por parte del Estado para prevenir, detener y sancionar la violencia contra la mujer constituyó una violación a las obligaciones de adoptar medidas adecuadas para eliminar la discriminación de la mujer en el ámbito privado.

Más específicamente hemos hallado incluso persecución por parte del Comité en casos donde aun habiendo legislación específica de violencia de género en el contexto de pareja, sin embargo, las autoridades no lograron impedir la muerte de las víctimas a manos de sus maridos, pese a las advertencias reiteradas de amenazas de muerte. Los asuntos Sahide Goekce v. Austria y Fama Yildirim v. Austria son ejemplificativos de este nuevo hacer por parte del Tribunal que ahora recomienda: fortalecer la aplicación y supervisión de la ley de protección contra la violencia familiar, utilizar los recursos legales disponibles para actuar cuando la violencia doméstica represente una amenaza peligrosa para la víctima, velar por la mayor coordinación entre funcionariado involucrado, y fortalecer los programas de capacitación y educación sobre violencia doméstica para la magistratura, abogacía y funcionariado competente (Courtis, 2010, 778).

Dicha conclusión abre una puerta a la necesidad de apostar de manera efectiva por la igualdad efectiva ciudadana, siendo responsable el Estado -de acuerdo al Derecho Internacional y Europeo- en caso de no tomar medidas para prevenir o reparar a las personas que sufren discriminación por motivos de género por parte de entidades y personas privadas (Women's Link Worldwide, 2011,211).

\section{LA CARTA SOCIAL EUROPEA: ENFOQUE SOCIO-LABORAL Y CIUDADANÍA EXCLUIDA.}

La Carta Social Europea es un Tratado Internacional elaborado por el Consejo de Europea, 
concerniente a los problemas sociales. Firmado el 18 de octubre de 1961, no fue ratificado por España hasta el 29 de abril de 1980. No obstante, la revisión posterior sufrida por la Carta en 1996 no ha sido aún ratificada por nuestro país.

Se compone de cinco partes y un anexo relativo al ámbito de aplicación en lo que se refiere a las personas protegidas. En la parte II se desarrollan, en 19 artículos, los derechos y principios que en la parte I se enuncian: derecho al trabajo; derecho a unas condiciones de trabajo equitativas; derecho a la seguridad e higiene en el trabajo; derecho a una remuneración equitativa; derecho sindical; derecho de negociación colectiva; derecho de los niños y adolescentes a protección; derecho de las trabajadoras a protección; derecho a la orientación profesional; derecho de formación profesional; derecho a la protección de la salud; derecho a la seguridad social; derecho a la asistencia social y médica; derecho a los beneficios de los servicios sociales; derechos de las personas físicas o mentalmente disminuidas a la formación profesional y a la readaptación profesional y social; derecho de la familia una protección social, jurídica, económica; derechos de las madres y los niños a una protección social y económica; derecho a ejercer una actividad lucrativa en el territorio de otras partes contratantes; derecho de los trabajadores emigrantes y sus familias a protección y a asistencia.

La Carta Social abarca pues ciertas protecciones, aunque siempre centradas en el ámbito socio-laboral, haciendo especial referencia a "niños y adolescentes", derechos de las personas físicas o mentalmente disminuidas a formación profesional o a su readaptación profesional, trabajadores emigrantes, mujeres y madres trabajadoras.

La Carta Social Europea menciona tanto en su Parte I, como en la Parte II, la protección "especial" de las trabajadoras, y el compromiso adquirido por las partes para conseguirlo. En este sentido, el punto 8 de la Parte I indica:"Las trabajadoras, en caso de maternidad, y las demás trabajadoras, en los casos procedentes, tienen derecho a una protección especial en su trabajo".

Dentro de esta especial protección de las mujeres en el trabajo se incluyen -Parte II, art.8- : una prestación por maternidad, el reconocimiento como ilegal del despido de una mujer durante su ausencia por este motivo, la garantía de tiempo para las madres para poder crías a su hijos, la regulación del trabajo nocturno de las mujeres en empleos industriales; y la prohibición del empleo femenino en trabajos subterráneos de minería y, en su caso, en cualesquiera otros trabajos que no sean adecuados para la mujer por su carácter peligroso, penoso e insalubre.

Sin embargo, no podemos desconocer varios aspectos. El primero de ellos descansa en que las mujeres pueden ser "niñas y adolescentes", "personas físicas o mentalmente disminuidas", "trabajadoras emigrantes" "madres o no", y sobre todo, trabajadoras reconocidas o no en tanto que especialistas en el trabajo reproductivo. Asimismo, centrar la protección en el ámbito socio-laboral, significaría dejar al margen a tantas mujeres que, pueden ser madres o no y que trabajan, aunque no sea en la esfera pública. Fijarse sólo en esos aspectos significaría, 
entre otras cosas, penalizar a las mujeres que como ciudadanas dedican su vida a trabajos - no pedidos, ni remunerados, ni prescindibles- que restarían residualmente, con míseras pensiones no contributivas otorgadas graciosamente por "papá Estado".

Tampoco puede desconocerse la subordinación estructural que padecen las mujeres en la esfera privada y pública que repercute, sin duda, en el ámbito laboral (si es que se pretende insistir en el mismo) y que significa aumento del paro (triplica), asignación de trabajos a tiempo parcial (cuadruplica), mayor precariedad laboral (contratos más cortos y temporales), y empleo con pobreza. Esto significa que el sesgo de género, reatraviesa todos los derechos sociales-laborales mencionados a lo largo del texto de la Carta Social Europea, aunque la estructura sexo-género no se mencione (a excepción de la protección especial del art. 8 ya señalada) y más aún sumados otros sistemas excluyentes como raza, color, discapacidad, edad, entre un largo etcétera. Entendemos que deben asumirse estos enfoques no de manera aislada, pues interseccionan entre sí (Lombardo et al,, 2009), sin olvidar la existencia de categorías o ejes fundamentales de subordiscriminación.

\section{ÚLTIMOS PRONUNCIAMIENTOS CONDENATORIOS DEL COMITÉ EUROPEO DE DERECHOS HUMANOS AL ESTADO ESPAÑOL}

No obstante, y con las deficiencias antes apuntadas, recientemente, en febrero de 2015, el Comité Europeo de Derechos Sociales (CEDS) ha llamado la atención al Estado español por la disconformidad de la legislación interna laboral con los preceptos reconocidos en la Carta Social Europea, durante el período de 1 de enero de 2009 a 31 de diciembre de 2012. La prueba de este corte transversal de la estructura sexo-género lo encontramos por ejemplo en las recientes medidas de reforma laboral adoptadas por el Gobierno (Ley3/2012), y convalidadas por el TC que, sin duda, repercuten duramente sobre las mujeres. Pese a la superación del trámite constitucional, esta reforma no supera el control de convencionalidad según el CEDS (Conclusiones XX-3 de 2014). Asimismo, el Comité Europeo refiere siete conclusiones de no conformidad con la Carta Social Europea que merecen ser mencionadas y observadas con la lupa metodológica del género.

Dichas conclusiones se refieren a: la insuficiencia del salario mínimo profesional; la flexibilidad de tiempo de trabajo; la compensación de las horas extraordinarias; las medidas compensatorias para personas trabajadoras expuestas a riesgos residuales para su salud; el período razonable de preaviso para la terminación del contrato, incluido el período de prueba en el contrato de apoyo a los emprendedores; la inaplicación unilateral del convenio colectivo; la injerencia del Gobierno en el ejercicio del derecho de huelga, a través del arbitraje obligatorio y la criminalización de la participación en huelgas.

Ya con anterioridad, el Comité Europeo de Derechos Sociales había señalado incumplimientos del Estado español (Conclusiones XX-2 (2013) en relación a los derechos del ámbito de la salud y la protección 
social (art. 3, 11, 12, 13, 14 de la CSE y art. 4 del Protocolo) con claras repercusiones de género, habida cuenta de la importante ratio de mujeres inmigrantes irregulares en nuestro país y de las dificultades de las mujeres para encontrar trabajo. En ellas se declaraba la disconformidad con la Carta Social Europea de las normas internas por las que se excluía del Sistema Nacional de Salud a las personas extranjeras por razón de su estatus irregular. Esta discriminación deriva del $R D$ 16/2012, de 20 de abril, de medidas urgentes para garantizar la sostenibilidad del Sistema Nacional de Salud y mejorar la calidad y seguridad de sus prestaciones y de la Ley 16/2003, de 28 de mayo, de cohesión de calidad del Sistema Nacional de Salud, y el RD 12/2012, que requería para estar asegurado la residencia legal en España, lo que implicaría la exclusión de facto de la asistencia sanitaria de las personas extranjeras en situación irregular, pero también excluía a las personas de nacionalidad española de 25 años sin cotizaciones previas, la mayoría mujeres. Tampoco podemos olvidarnos de la especial vulnerabilidad de las mujeres inmigrantes -sin papeles- que, en el mejor de los casos, se dedican a empleadas de hogar y/o cuidado de personas dependientes, o a la prostitución o víctimas de mafias de trata de seres humanos.

El Comité Europeo de Derechos Sociales desecha en su último informe el argumento de la crisis como justificativo de restricciones legales en derechos sociales incluidos en la Carta Social Europea y que, por el contrario, deben ser "especialmente garantizados" en estos momentos.

Sin embargo, un inevitable análisis con perspectiva de género a los actuales Presupuestos Generales del Estado de 2016 nos permitirá concluir el abandono de la protección de los derechos ciudadanos (Manifiesto Feminista sobre los Presupuestos Generales del Estado para 2016). 3 claves de partida:

\section{Desempleo y pobreza.}

La reducción de un 22\% de la partida de prestaciones ahondará la ya existente brecha de género (22,55\% o trabajar 82 días más al año que el varón y ser diplomada universitaria), habida cuenta de que las mujeres cuadruplican su presencia en trabajos a tiempo parcial y de corta temporalidad. Son empleos con pobreza e implican a su vez parcialidad salarial, de promoción profesional y de prestaciones sociales incluidas las de jubilación. En estos últimos cuatro años (2012-2015) la brecha entre la Tasa de paro de mujeres y hombres se ha triplicado. Resulta obligado insistir en la omisión del análisis de género en los ingresos y Seguridad Social, cuando las pensiones contributivas y no contributivas vuelven a subir en 2016, el 0,5\%, y las pensiones de viudedad están en el centro del debate, siendo las mujeres el 93\% de los 2,3 millones de personas que viven de ellas.

Asimismo, se ha reducido la financiación a los ayuntamientos -Ley 27/2013 de reforma de la Ley de Régimen Local- que deja sin recursos a los servicios sociales base, lo que desde una visión de género alerta del abandono de las mujeres y de su prole a la más absoluta pobreza. Es lo que se ha venido llamando feminización de la pobreza. Como muestra, un botón: el $72 \%$ de las personas beneficias del programa de solidaridad para personas 
con riesgo de exclusión social de la Junta de Andalucía, son mujeres.

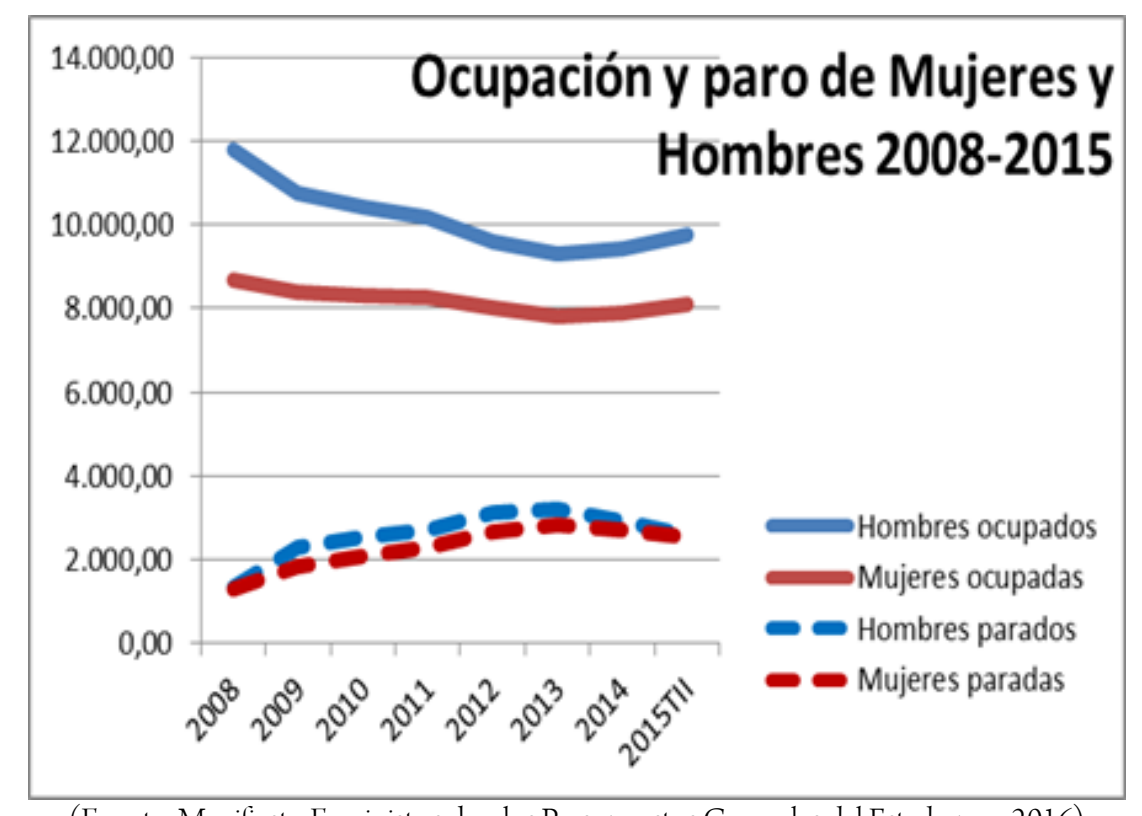

(Fuente: Manifiesto Feminista sobre los Presupuestos Generales del Estado para 2016)

Trabajo de cuidados.

El trabajo reproductivo (sin remuneración ni reconocimiento) sigue estando en manos de las mujeres lo que repercute, ineludiblemente, en las condiciones laborales, nivel de ocupación y tipo de empleo. Si a ello le sumamos la suspensión de la ampliación del permiso de paternidad, la falta de dotación de escuelas infantiles de 0 a 3 años o la nimia subida en dependencia, destinada a disolverla, el empuje y destierro de las mujeres al hogar es inevitable. En 2014 se tramitaron 31.435 excedencias por cuidado de hijo/as, de las cuales el 94\% fueron tomadas por mujeres, porcentajes que se ha mantenido en 2015 (92\%). No olvidemos tampoco que el $97 \%$ de las personas que cuidan a personas dependientes son mujeres y que 500.000 personas perdieron la ayuda a domicilio. 


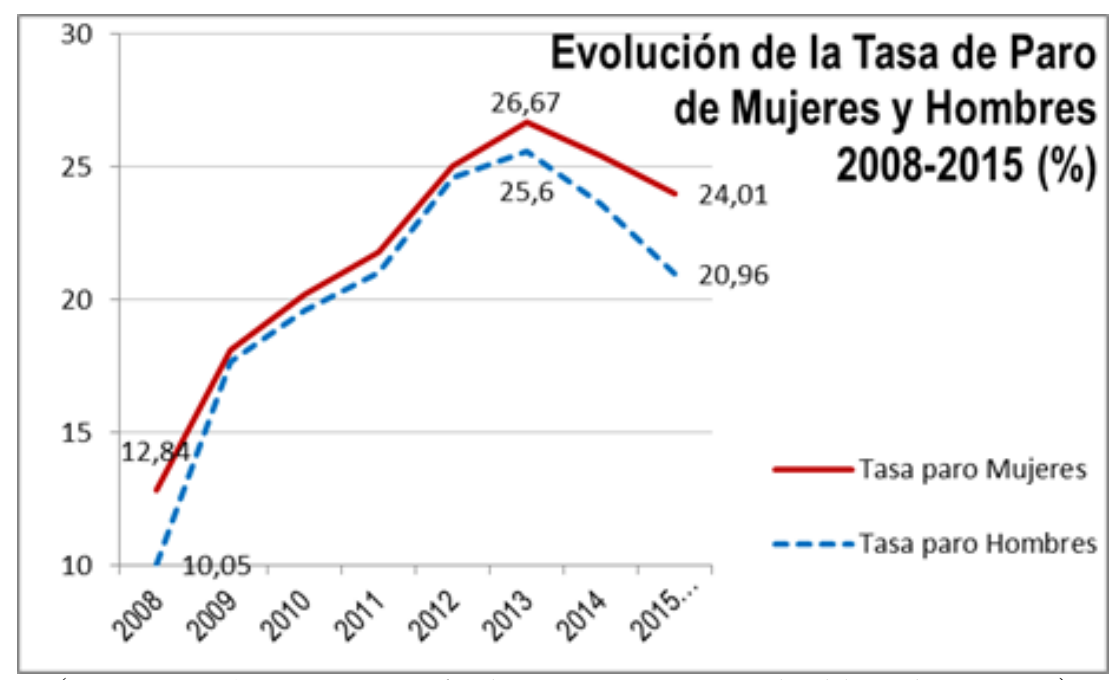

(Fuente: Manifiesto Feminista sobre los Presupuestos Generales del Estado para 2016)

\section{Violencia de género en el contexto de pareja.}

Los PGE han aumentado en un 6,3\% los recursos destinados a violencia de género en el contexto de pareja, pero siguen estando por debajo de los niveles de 2009 (baja el 10,92\%), resultando claramente insuficientes para afrontar esta lacra social. Con la crisis, en apenas tres años, se han reducido en $30 \%$ los fondos para prevenir la Violencia. Ya en 2015 se pretendió corregir la cifra incrementando un 8.6\% estas partidas (aumentando la partida de Igualdad Efectiva a 20,82 millones y 23,7 millones la de Violencia de Género), pero esto supone, en conjunto el 0,01\% del presupuesto total, además de ser una cantidad insuficiente para suplir el recorte de los Ayuntamientos antes referido. Esto ha supuesto el cierre de cas as de acogida, Centros de la Mujer y la destrucción de 5.000 puestos de trabajo (Gil Ruiz, 2014, 11).

Por supuesto, mucho hay que decir sobre la escasez de recursos para formación en género, exclusión en los curricula de asignaturas formativas al respecto, y centralización del enfoque de la violencia en el plano penal (aun deficitaria) en detrimento de la igualdad y del consecuente recorte en medidas educativas, preventivas y sociales. Un dato más de la confluencia de factores discriminatorios en las mujeres lo constata además el nada desdeñable incremento de la violencia de un $33 \%$ en las mujeres con discapacidad. 


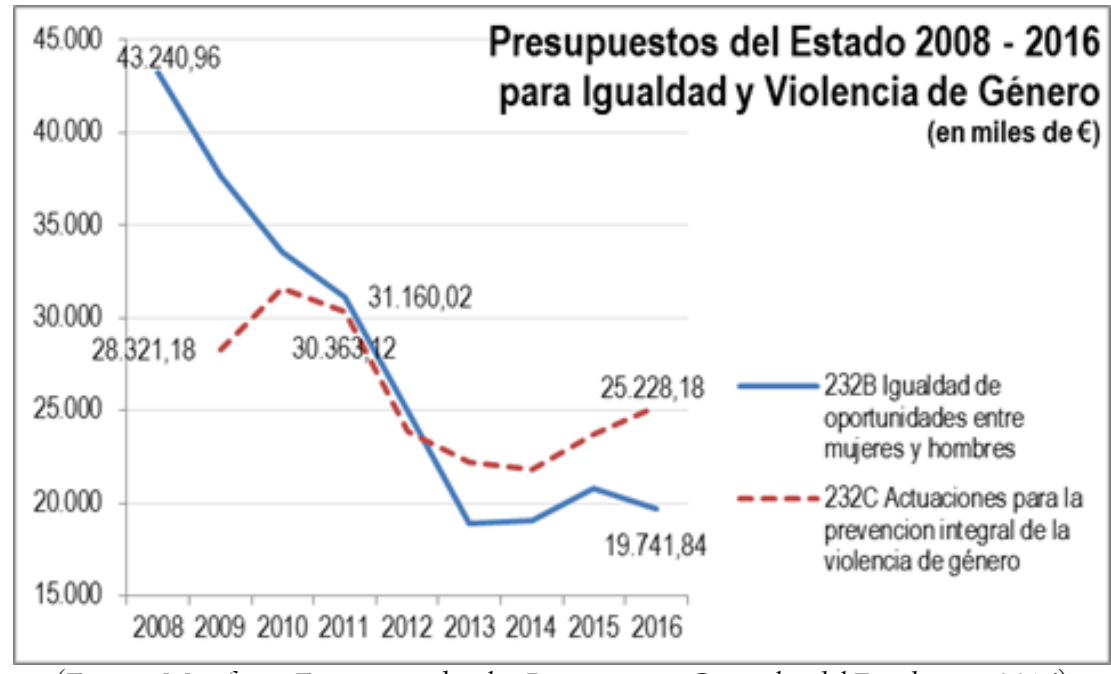

(Fuente: Manifiesto Feminista sobre los Presupuestos Generales del Estado para 2016)

Aun así, y pese a la deficiente regulación (centrada en lo socio-laboral) de la Carta Social Europea, no debe desconocerse el Protocolo Adicional a la Carta ratificado por España en Estrasburgo el día 5 de mayo de 1988, publicado en el BOE no 99, de 25 de abril de 2000, pp. 16074-8. Tras publicarse la corrección de errores en el BOE no 220, de 13 de septiembre de 2000, entró en vigor el 23 de febrero de 2000. En su lectura comienza a detectarse su preocupación por la igualdad de oportunidades y de trato en materia de empleo y de profesión sin discriminaciones por razón de sexo, como objetivo de su política (parte I), la vinculación de las partes (parte II), los compromisos (parte III), la supervisión de la observancia de los compromisos contraídos (parte IV), y su aplicación (parte $\mathrm{V})$.

\section{EVOLUCIÓN DEL PRINCIPIO DE NO DISCRIMINACIÓN Y EL MODERNO DERECHO ANTIDISCRIMINATORIO.}

Tanto el Convenio Europeo para la Protección de los Derechos Humanos y de las Libertades Fundamentales, como la Carta Social Europea, hacen referencia en sus Preámbulos a los Tratados Internacion ales vinculantes adoptados por los Estados, así como en la Jurisprudencia del TEDH arriba analizada. En este sentido, el acercamiento a algunos de ellos y la evolución del principio de no discriminación, originario de un nuevo marco de Derecho Antidiscriminatorio, resultan fundamentales para entender la reconfiguración de la igualdad basada en un nuevo modelo de ciudadanía, esta vez sí inclusivo de todos los seres humanos en su diversidad (Schiek y Chege, 2009).

El 18 de diciembre de 1979 se adoptó por la Asamblea General de Naciones Unidas, la conocida como CEDAW, la Convención de Naciones Unidas sobre la eliminación de todas las formas de discriminación contra la(s) mujer(es). España la ratificará en 1983. Actualmente podemos decir que ha sido ratificada y/o adherida por una total de 187 países, incluyendo a Afganistán. EEUU y Sudán del Sur la habían firmado, aunque no ratificado. 
Faltan 8 países para completar la totalidad del globo terráqueo: Irán, Nauru, Palaos, Catar, Somalia, Sudán, Tonga y El Vaticano (Gil Ruiz, 2013).

Esta Convención, aunque no fuera exactamente el texto que las organizaciones de mujeres anhelaban, fue un primer paso, un hito en lo que a la historia por la igualdad de género se refiere. Algunos aspectos merecen ser destacados: la definición jurídica de "discriminación contra la mujer" (art. 1), la incorporación de un programa de acción para los Estados parte (art. 3), así como medidas de acción positiva diferenciadora (art. 4); y la vinculación de éstos (los Estados parte) (art. 2), hasta el punto de asignarles -en la Resolución 45/1994, de la Comisión de Derechos Humanos- responsabilidades, ya fuere por acción y u omisión, por actos de violencia contra las mujeres.

Según la CEDAW se entiende como discriminación contra la mujer, "toda distinción, exclusión, o restricción basada en el sexo que tenga por objeto o por resultado menoscabar o anular el reconocimiento, goce o ejercicio por la mujer, independientemente de su estado civil, sobre la base de la igualdad del hombre y la mujer, de los derechos humanos y las libertades fundamentales en las esferas política, económica, social, cultural y civil o en cualquier otra esfera”. Ello implicaba- en el consenso internacional- la conceptualización jurídica de lo que era discriminación contra la mujer, y cómo ésta podría ejercerse no sólo en la esfera privada sino en la pública. La inmediata vinculación entre discriminación y violencia de género estaba servida.

No obstante, no será hasta pasada más de una década, cuando tras la III Conferencia Mundial de la Mujer de Nairobi en 1985, el Comité encargado de velar por el cumplimiento efectivo de la CEDAW, incorpore la violencia expresamente como forma discriminación, llegando a la conclusión, en el párrafo 4 de la Recomendación General no 19, que "los informes de los Estados parte no siempre reflejaban de manera apropiada la estrecha relación entre la discriminación contra la mujer, la violencia contra ellas y las violaciones de los derechos humanos y las libertades fundamentales".

Esta estrecha relación entre violencia contra las mujeres y discriminación, es lo que se viene llamando los diferentes rostros de la violencia de género (Gil Ruiz, 2007) concepto que supera y engloba con mucho la violencia de género en el contexto de pareja (Lousada Arochena, 2014), pero que visibiliza una máxima fundamental: que no se puede erradicar la violencia de género en el contexto de pareja, si antes no se visibiliza y combate la violencia estructural que padecen las mujeres no sólo en la esfera privada (cima del iceberg), sino en la pública. Y esto significa admitir que la violencia (sean cuales fueren las conductas designadas por esta expresión) es el componente necesario de un sistema de subordiscriminación (Barrère Unzueta, 2014, 159).

No obstante, todo ello apunta otra forma de hacer Derecho, dirigido por y hacia otro modelo de ciudadanía, esta vez inclusivo de todos los seres humanos, en sus diferencias, y no encorsetados en el modelo de varón (blanco, adulto y propietario), heredado de la Modernidad. Ya no hablamos de un ciudadano que parte de 
la plantilla humana de varón -como veremos en el siguiente epígrafe-, sino de una ciudadana que posee intereses y reivindicaciones tan propias a su sexo y humanidad, como intereses y reivindicaciones propias poseen los hombres como ciudadanos.

En definitiva, habría que superar los esquemas conceptuales del Derecho liberal, incluido el Derecho antidiscriminatorio clásico, dando cabida al sistema sexo-género en el Derecho y en la cultura jurídica de forma prioritaria y transversal, para así poder reconfigurar el principio de igualdad y el modelo de ciudadanía que lo sustenta (Rubio y Gil Ruiz, 2012, 71).

\section{Datos de una exclusión.}

Dicho esto, hay que partir de la realidad sociológico-política y de los datos. Para poder participar en la vida social, jurídica y política como ciudadana (que no como colectivo vulnerable), para poder tener voz, debía constatarse la máxima de su existencia. Si no se está no se puede participar, por mucho que en teoría el concepto de "ciudadana" golpee sin cesar los textos internacionales y nacionales, y por mucho que se diga que componen el $50 \%$ de la humanidad global.

Los datos facilitados por la ONU en la actualidad (Murguialday Martínez, 2009) y que paso a exponer, confirmarán aún hoy el diagnóstico de necesidades, la invisibilidad en los ámbitos destacados por el Gobierno de vital importancia, y la urgencia de incorporar la perspectiva de género en el Derecho para erradicar toda forma de discriminación y exclusión; y de consecución de la igualdad efectiva de la ciudadanía.

\begin{tabular}{|c|c|c|c|}
\hline Mujeres (\%) & & Hombres (\%) & Diferencia \\
\hline 50 & Población & 50 & 0 \\
\hline 52 & Horas trabajadas & 48 & 4 \\
\hline 10 & Dinero en propiedad & 90 & -80 \\
\hline 1 & Tierra en propiedad & 99 & -98 \\
\hline 67 & Pobres & 33 & 34 \\
\hline
\end{tabular}




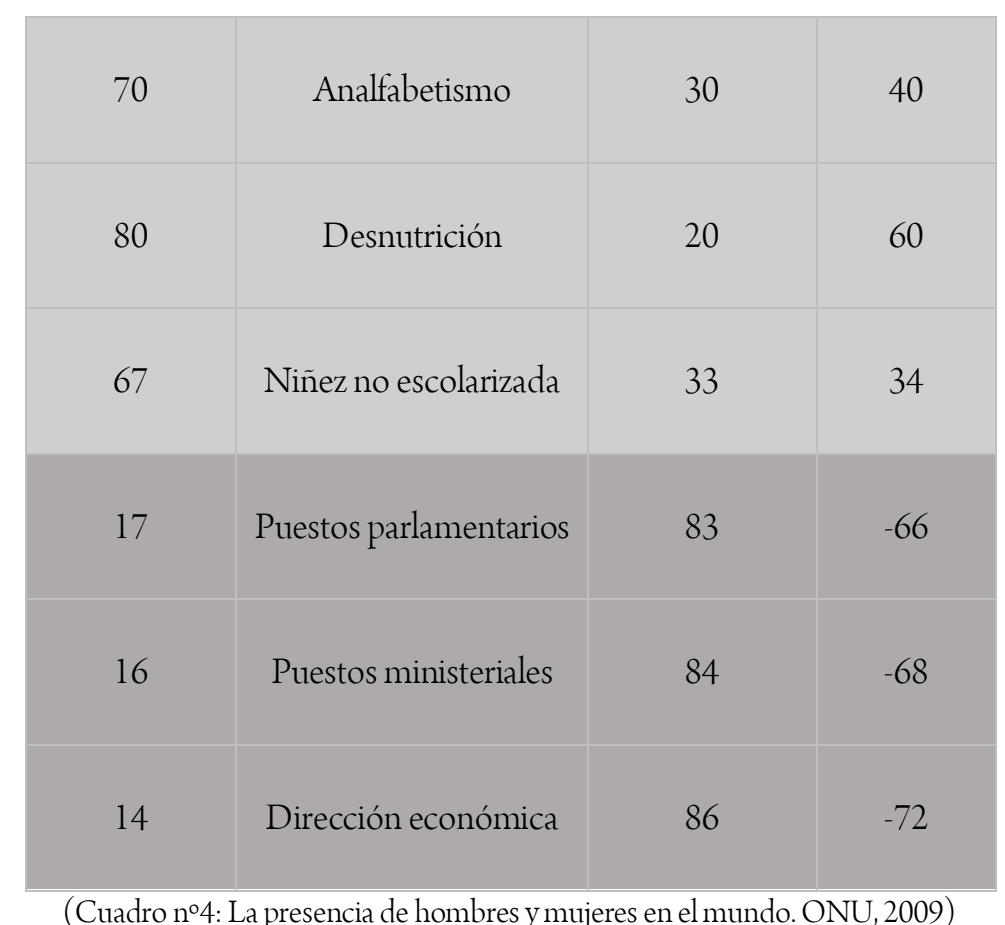

Este cuadro que marca la bochornosa desigualdad de género en el mundo, marca el segundo de los aspectos que deberíamos de perseguir. Si el primero se centra en la necesidad de incorporar la perspectiva de género en las disposiciones normativas y no normativas que elabore el gobierno (otro Derecho y otra Política), el segundo descansa en la necesidad y urgencia de garantizar la presencia equilibrada y activa de las mujeres en los órganos de decisión política y económica, especialmente relevantes. Nunca un cuadro ha podido ser más expresivo sobre la escandalosa desigualdad de género mundial y tan explícito en torno a por qué un tercio $(1 / 3)$ de la población mundial, según la OMS, ha sufrido Violencia de Género por parte de su pareja o expareja; por qué un 38\% de los asesinatos de mujeres en el mundo se deben a Violencia de Género; por qué 7 de cada 10 mujeres en México ha sufrido alguna vez violencia en su vida; o por qué -aterrizando en España y según el Centro de Investigaciones Sociológicas-, 600.000 mujeres ha sufrido algún tipo de violencia de género, pese a que sólo se denuncien 120.000 .

Y esto es así, pese a que la II Conferencia Mundial sobre la Protección de los derechos humanos, celebrada en Viena en junio de 1993, elevara el pleno disfrute de los derechos de las mujeres a "prioridad para los gobiernos y para las Naciones Unidas" y que la igualdad de la mujer y sus derechos deban integrarse en las principales actividades en todo el sistema de Naciones Unidas". Sin duda se requiere no sólo la presencia activa de mujeres, sino que las voces de éstas sean escuchadas y recogidas en las agendas públicas de los Estados (Lépinard, 2006). No obstante, aunque un mero incremento en el número de mujeres elegidas no sabemos si se traduciría automáticamente en ganancias políticas para las mujeres (Celis et al,,2008, 102), sería un primer paso insoslayable de replanteamiento de equilibrio democrático. 


\section{Beijing y Ámsterdam: la integración del gender mainstreaming en el Derecho Internacional.}

Como no podía ser de otro modo, tras Nairobi, la IV Conferencia Mundial sobre la Mujer celebrada en Beijing, en 1995, renovó el compromiso de la comunidad internacional para lograr la igualdad entre los géneros, así como el desarrollo y la paz para todas las mujeres. En la misma se invitó a todos los gobiernos y a los demás agentes a integrar la perspectiva de género (gender mainstreaming) -como corriente principal- en las legislaciones, en las políticas, programas y proyectos públicos para analizar sus consecuencias para las mujeres y los hombres respectivamente, antes de tomar decisiones. Posteriormente, este compromiso ha sido reconfirmado en numerosas ocasiones, persiguiendo y analizando los mecanismos para incrementar la responsabilidad de los gobiernos en el cumplimiento del mandato que figura en la Plataforma de Acción.

Sin embargo, la traducción confusa en la versión en español del Punto IV de la Plataforma de Acción aprobada en la IV Conferencia Mundial sobre la Mujer en Beijing en 1995, dificulta el sentido del gender mainstreaming, que no pretende sólo introducir transversalmente la perspectiva de género, sino dotar a esta perspectiva (frente a otras) de un carácter principal. Y es que la referencia idiomática a su introducción, concretamente en el punto IV de la Plataforma ( $8^{\circ}$ objetivo estratégico) no resulta baladí. Así, según la versión inglesa de este documento, la principal tarea de los mecanismos institucionales (nacionales) para el adelanto de las mujeres sería "to support governement-wide mainstreaming of a gender-equality perspective in all policyareas" (párrafo 201) es decir, ("apoyar como corriente principal (mainstreaming) a escala gubernamental una perspectiva de género en todas las políticas" (énfasis añadido) y "(to) promote an active and visible policy of mainstreaming a gender perspective in all policies and programmes" (párrafo 202), esto es "promover una política activa y visible que eleve a corriente principal (mainstreaming) la perspectiva de género en todas las políticas y programas" (énfasis añadido). (Barrère Unzueta, 2010, 240-241).

Sin embargo, en la versión española se traduce esa referencia señalando que la principal tarea de dichos mecanismos sería "apoyar la incorporación en todos los órganos gubernamentales de una perspectiva relativa a la igualdad entre los géneros en todas las esferas normativas", y "la incorporación de las cuestiones de género ... (en) todas las políticas y los programas". Es decir, en la versión española se traduce "mainstreaming" simplemente por "incorporación", perdiendo de este modo la connotación en relación al término raíz "mainstream" ("corriente principal")".

Europa -en el marco de la Unión Europea- no ha quedado al margen de este compromiso con la igualdad efectiva inter-géneros pasando a formar parte de una de las prioridades de su agenda política. No en vano, se trata de "un principio firme y creciente, en el seno de la Unión Europea. En efecto, ha sido reconocido por el art. 3 del Tratado de Ámsterdam, que ha incluido, como de una de las prioridades a tener en cuenta en el diseño de 
Políticas Europeas, la promoción de la Igualdad de mujeres y hombres en todas las políticas y la eliminación de las discriminaciones. Se incluye como objetivo de la Unión, la promoción de la igualdad entre hombres y mujeres (hasta el punto de condicionar) el conjunto de las Políticas Comunitarias al objetivo de la consecución de esa igualdad" (Rey Martínez, 2004). De este modo, el fin de la igualdad no se alcanza a través de una o varias acciones específicas, sino integrándolo en todas las acciones.

El artículo 3.2 del Tratado de Ámsterdam explicita claramente el objetivo de la Unión Europea: "En todas las actividades contempladas en el presente artículo, la Comunidad se fijará el objetivo de eliminar las desigualdades entre el hombre y la mujer y promover su igualdad". El reciente Tratado de Lisboa se pronuncia en idénticos términos en su artículo 8: "En todas sus acciones, la Unión se fijará el objetivo de eliminar las desigualdades entre el hombre y la mujer y promover su igualdad".

En este sentido, "la Comisión de la Unión Europea ante la constatación de que decisiones políticas que, en principio, parecen no sexistas, pueden tener un diferente impacto en las mujeres y en los hombres, a pesar de que dicha consecuencia ni estuviera prevista ni se deseara, aprobó (en 1996) una Comunicación sobre la transversalidad mainstreaming -introduciéndola en el Tratado de Ámsterdam (1997)- como un primer paso hacia la realización del compromiso de la Unión Europea de integrar la perspectiva de género en el conjunto de las políticas comunitarias y elaboró una Guía para la Evaluación del Impacto en Función del Género (1998) diseñada para proyectarse en el seno de la Comisión con objeto de evitar consecuencias negativas no intencionales que favorezcan situaciones de discriminación y para mejorar la calidad y la eficacia de las políticas comunitarias" (Exposición de Motivos de la Ley 30/2003, de 13 de octubre, sobre medidas para incorporar la valoración del impacto de género en las disposiciones normativas que elabore el Gobierno).

De este modo, y como complemento a los objetivos de la acción comunitaria prevista para la promoción de la igualdad efectiva de mujeres y hombres, merece destacarse la aprobación de la Decisión del Consejo 2001/51/CEE, de 20 de diciembre de 2000, por la que se establece un programa de acción comunitaria (V Programa Marco) sobre la estrategia (COM 2000, 335 final) que debe seguirse en materia de igualdad de mujeres y hombres (2001-2005), sustentándose en los principios derivados de la transversalidad y en la Hoja de ruta para la igualdad entre hombres y mujeres 2006-2010. Este Programa Marco, de enfoque dual, "es uno de los instrumentos necesarios para la puesta en práctica de la estrategia global comunitaria en materia de igualdad entre mujeres y hombres, que abarca todas las políticas y todas las acciones comunitarias encaminadas a alcanzar dicha igualdad, incluidas las políticas de integración de la igualdad de los sexos y las acciones específicas dirigidas a las mujeres", y destaca por conceder un especial protagonismo a la evaluación del impacto de género en todos los ámbitos de intervención (vida económica, social, política, vida civil, roles y estereotipos,...) que tengan repercusiones directas o indirectas en las mujeres o en los hombres, "como una de las acciones a emprender para 
el logro de los objetivos mencionados en el referido programa” (Decisión del Consejo 2001/51/CEE, de 20 de diciembre de 2000). Ello explica el sentido de la transversalidad y exige que "en el diseño y aplicación de todas las políticas hay (a) que tener en cuenta las preocupaciones, las necesidades y aspiraciones de las mujeres, en la misma medida que las de los hombres". (Comunicación de la Comisión al Consejo, al Parlamento Europeo, al Comité Económico y Social y al Comité de las Regiones, relativa a una Estrategia Marco Comunitaria sobre igualdad de hombres y mujeres (2001-2005).

\section{Ámbitos de intervención para la reconfiguración jurídica basada en un nuevo modelo ciudadano.}

Tal y como hemos señalado, el modelo de políticas públicas existente en el mundo, y por supuesto en Europa, no ha sido pensado con la idea de garantizar la equidad de género. De hecho, más de dos tercios de las personas analfabetas del planeta son mujeres, porque acceden en menor medida que los varones a la educación. Asimismo, las personas son titulares de importantes derechos sociales en función de su posición en el mercado de trabajo, y ello implica -en tanto que la vinculación de las mujeres es menor y sus condiciones de precariedad son mayores que la de los compañeros varones- una penalización, o mejor dicho, una discriminación en el acceso a los derechos sociales derivados del empleo, como las pensiones de jubilación.

Por esta razón, los ámbitos de intervención, antes mencionados, en los que debe aplicarse el principio de transversalidad a los que se refiere la normativa comunitaria son:

I. Ámbito económico ysocial: concibiendo estrategias para fomentar la integración de la igualdad en todas las políticas que tengan repercusiones sobre la mujer en materias como la política fiscal, financiera, económica, educativa, de transporte, de investigación y social, la estrategia europea de empleo, así como la utilización de los fondos estructurales para promover la igualdad.

II. Participación y representación en los órganos de decisión: mejorando el equilibrio de mujeres -en tanto que ciudadanas- y hombres -en tanto que ciudadanos- en la toma de decisiones políticas y socioeconómicas.

III. Acceso y pleno disfrute de los derechos sociales para las mujeres y los hombres, mejorando el conocimiento de éstos, así como extremando la vigilancia de la aplicación de la legislación existente en el ámbito social en materia de contratos atípicos, condiciones de trabajo y conciliación. Asimismo, se velará por la aplicación y evaluación de las politicas y actividades que tienen una repercusión en la vida diaria de mujeres y de hombres, como la política de transporte, la salud pública, las relaciones exteriores, incluidos el programa comunitario de lucha contra la discriminación fundamentado en el art. 13 del Tratado CE y las políticas relativas a los derechos humanos. 
IV. Vida civil: procediendo al seguimiento, difusión y control de aplicación de la legislación y la jurisprudencia comunitaria en materia de igualdad de trato entre mujeres y hombres; reconociendo y promoviendo el reconocimiento de los derechos específicos de la mujer como derechos humanos universales; y luchando contra la violencia sexista y la trata de seres humanos con fines de explotación sexual.

V. Cambio de roles y estereotipos masculinos y femeninos: apostando por campañas de sensibilización y de formación en género, a través de la educación, medios de comunicación, la cultura y la ciencia. Se deben erradicar los prejuicios y estereotipos sexistas que ponen de manifiesto la falta de reconocimiento de la mitad de la ciudadanía y la transmisión de valores subordinadores y jerarquizantes.

En esta línea, y abundando en esta exigencia, la Comisión Europea incluyó el Informe de Impacto de Género como requisito en el Reglamento de los Fondos Estructurales de 1999, para la elaboración de los Planes de Desarrollo Regional para el período 2000-2006. El requisito que debía acompañar a los Planes de Desarrollo Regional era:

"c) una evaluación previa de la situación en términos de igualdad entre hombres y mujeres por lo que se refiere a oportunidades en el mercado de trabajo y al trato en el trabajo, incluyendo las dificultades específicas de cada grupo; una estimación del impacto esperado de la estrategia y de las intervenciones, en particular en lo referente a la integración de mujeres y hombres en el mercado de trabajo, a la educación y la formación profesional, la capacidad empresarial de las mujeres y a la conciliación de la vida familiar y profesional".

Para reforzar su vinculación y obligatoriedad para el Derecho interno de los distintos Estados miembros, la Unión Europea exigía transponer una Directiva de vital importancia en lo que al principio de transversalidad se refiere; a saber: la Directiva 2002/73/CE, de 23 de septiembre de 2002, del Parlamento Europeo y del Consejo, de modificación de la Directiva 76/207/CEE, de 9 de febrero de 1976, relativa a la aplicación del principio de igualdad de trato entre hombres y mujeres en lo que se refiere al acceso al empleo, a la formación y a la promoción profesionales, y a las condiciones de trabajo. Su artículo 1.3 es rotundo al respecto:

"los Estados miembros tendrán en cuenta de manera activa el objetivo de la igualdad entre hombres y mujeres al elaborar y aplicar disposiciones legales, reglamentarias y administrativas, así como políticas y actividades, en los ámbitos contemplados en el apartado $1 "$.

Y en este orden de cosas, los Estados miembros, según la nueva redacción del artículo 3.2.a), están obligados a adoptar "las medidas necesarias para garantizar que... se derogue cualquier disposición legal, reglamentaria o administrativa contraria al principio de igualdad de trato". La anterior redacción de su articulado art. 3.2.a), 4.a) y 5.2.a)- obligaba a adoptar "las medidas necesarias a fin de que se supriman". Aunque parezca que el matiz es mínimo, la nueva redacción exige un plus, una adicional garantía de integración: la garantía de derogación, garantía que podría venir de la mano de los organismos de igualdad.

En otras palabras: 
"No basta con establecer medidas de supresión de las normas discriminatorias, como los controles judiciales de constitucionalidad de las leyes o de legalidad de los reglamentos, siendo necesaria la derogación normativa, instituto jurídico de eficacia general y competencia sólo del órgano normativo" (Lousada Arochena, 2004, 3).

No obstante, y sin entrar a mayores, la puesta en práctica del principio de transversalidad de las políticas comunitarias ha atravesado grandes dificultades (Woodward, 2008, 289-302), señaladas incluso en el Informe de la Comisión sobre el seguimiento de la Comunicación (98 122 final) que recaen en tres puntos fundamentales: "Se trata de la insuficiente concienciación sobre asuntos de género en los niveles en que se adoptan las decisiones, de la carencia de recursos humanos y presupuestarios destinados a estas tareas y de la falta de expertos en asuntos de género. Según la Comisión deberían superarse estos obstáculos para poder aplicar, como procedimiento habitual, la evaluación del impacto en función de género de las políticas, y para garantizar la calidad, en cuanto al género, de toda propuesta legislativa o cualquier otro documento político o acción de la Comunidad respecto al objetivo de la igualdad de oportunidades" (Rodríguez-Piñero, 2004, 36). Los tres caballos de batalla todavía por afrontar son claros: sensibilización y concienciación en torno a la igualdad de género; dotación presupuestaria; y apuesta seria por la formación en género. De cualquier modo, el avance por parte de la Unión Europea en la línea de los Tratados Internacionales antes referidos, ha abierto campo a un Consejo de Europa conservador y apegado al concepto de discriminación clásico liberal, ya superado y desfasado, de tradición aristotélica.

\section{La respuesta española al mandato del gender mainstreaming.}

El legislativo español, en esta línea de trabajo e impulsado por las demandas internacionales (Beijing, 1995) y europeas (Tratado de Ámsterdam y Tratado de Lisboa), ha apostado recientemente, por un nuevo Derecho antisubordiscriminación que debe incorporar la perspectiva de género, de manera transversal y principal. Esta integración de la dimensión de la igualdad de oportunidades en la totalidad de los procesos normativos -elaboración, interpretación y aplicación- de la totalidad de las normas y en la totalidad de las políticas públicas -se manifiesten a través de normas o de actos administrativos no normativos-, se denomina transversalidad, traducción, como sabemos, del neologismo inglés gender mainstreaming.

Resultado de este esfuerzo legislativo (Gil Ruiz, 2010, 45-82) son las (des)conocidas y polémicas Ley Integral (L.O. 1/2004, de 28 de diciembre), Ley de Igualdad (L.O. 3/2007, de 22 de marzo), sin olvidarnos de la Ley 30/2003, de 13 de octubre, sobre medidas para incorporar la valoración del impacto de género en las disposiciones normativas, encabezadas, sin duda, por los artículos 9.2 y 14 de la Constitución Española. Sin duda, el artículo 2.k) de la Ley Integral, y con mayor amplitud, el artículo 15 de la Ley de Igualdad, han supuesto la consagración expresa del principio de transversalidad, con la asunción lógica de todas sus consecuencias: la universalidad de la Igualdad y la integración de la dimensión de género

En cuanto a la primera, la Universalidad de la Igualdad, hablamos no sólo de una universalidad subjetiva, 
que afecta a todos los Poderes Públicos, sino objetiva, dirigida a todas las Ramas del Ordenamiento Jurídico. El artículo 15 de la Ley de Igualdad establece la vinculación transversal de la igualdad "en la actuación de todos los Poderes Públicos" y esta universalidad subjetiva la ratificará su carácter de norma básica, tal y como se recoge en la Disposición adicional 1a de la Ley.

La universalidad objetiva se contemplará, siguiendo la lectura del artículo 15 de la Ley de Igualdad, no sólo cuando alude a la "adopción y ejecución de sus disposiciones normativas", sino a "la definición y presupuestación de políticas públicas en todos los ámbitos y en el desarrollo del conjunto de todas sus actividades".

En cuanto a la segunda, la integración de la dimensión de género, en el proceso de elaboración de normas legislativas a propuesta del Gobierno, se modifica el apartado 2 de artículo 22 de la Ley 50/1997, de 27 de noviembre, del Gobierno, en el sentido de que "el procedimiento de elaboración de anteproyectos de Ley ( ... ) se iniciará en el Ministerio o Ministerios competentes mediante la elaboración del correspondiente Anteproyecto, que irá acompañado por $(\ldots)$ un informe sobre el impacto por razón de género de las medidas que se establecen en el mismo". En este mismo sentido, y en cuanto a la integración de la dimensión de género en el proceso de elaboración de normas reglamentarias emanadas del Gobierno, se añade un párrafo 1.b) del artículo 24 de la Ley 50/1997, de 27 de noviembre, del Gobierno, afirmando que "en todo caso, los reglamentos deberán ir acompañados de un informe sobre el impacto por razón de género de las medidas que se establezcan en el mismo". Posteriormente, la Ley de Igualdad de 2007, en su artículo 19, ampliará tal exigencia a "los proyectos de disposiciones de carácter general y los planes de especial relevancia económica, social, cultural y artística que se sometan a la aprobación del Consejo de Ministros".

Lamentablemente, estudios recientes (Gil Ruiz, 2012; 2013) constatan que el seguimiento por parte de España de este mandato y su implementación no está siendo el correcto. Los preceptivos Informes de Evaluación de Impacto de Género (IEIG), inexistentes en algunos casos y descuidados en su ejecución en otros, no ha servido, sino todo lo contrario, para acortar la brecha de estructural de desigualdad de la ciudadanía, sino que la ha engrosado, pero esta vez desde el procedimiento legislativo y ejecutivo en cuestión. Asimismo, su no persecución y fiscalización por parte del Poder Judicial permite que su teórica efectividad sea más que decepcionante, y que se legitime, a través de un procedimiento vacuo de perspectiva de género, no motivado, la adopción de una medida legislativa, administrativa y/o política que perpetuará la subordinación estructural inter-géneros, con apariencia de igualdad o, mejor dicho, travestido de transversalidad.

Asimismo, este nuevo hacer jurídico -el nuevo Derecho antidiscriminatorio y antisubordinación- exige romper con una estructura de trabajo primitiva y desfasada -aunque dogmáticamente incorporada, incluso por las Facultades de Derecho- de funcionamiento del fenómeno jurídico, y de los criterios básicos de igualdad - 
tradicional desde Aristóteles en el pensamiento occidental- y de discriminación -centrada en un contexto individual, que no estructural y grupal-, que maneja, y eso incorpora un plus de dificultad especialmente relevante.

Centrándonos en un marco de trabajo, la elaboración por el Gobierno de informes periódicos sobre la igualdad efectiva de género, la adecuación de las estadísticas y estudios desagregados por sexos, y la diagnosis previa en los Informes de Evaluación de Impacto de Género (IEIG), serviría para constatar la situación de partida de desigualdad real, y así arbitrar las medidas jurídico-políticas adecuadas para no perpetrar discriminación, esta vez, a través del Derecho y de la acción política. Asimismo se requieren: cambios institucionales dirigidos a erradicar la discriminación difusa estructural y legal existente; y políticas públicas comprometidas que, en una doble dimensión, remuevan - previa visibilización- los obstáculos que dificulten o imposibiliten la participación de la ciudadanía "mujeres" en la vida social, económica, cultural y política de los pueblos, y promuevan las condiciones para que ésta sea una realidad. Y para ello, el compromiso de los responsables políticos y de los poderes públicos hacia el objetivo de la igualdad de género no puede ser menor, ni residual, sino prioritario.

Aquí descansa el sentido -y el éxito- del mandato internacional y europeo de la integración del gender mainstreaming en el ordenamiento jurídico y político, como corriente principal. No se trata de una mera incorporación formal y/o accidental de las cuestiones de género en las propuestas normativas y políticas, sino que se convierta en instrumento básico y esencialde las políticas públicas. De otro modo, se seguirán perpetuando las violencias de género hacia las mujeres, esta (y otra) vez de la mano del Derecho y del Estado.

\section{LA DISCRIMINACIÓN ESTRUCTURAL DE GÉNERO Y EL CONVENIO DEL CONSEJO DE EUROPA SOBRE PREVENCIÓN Y LUCHA CONTRA LA MUJER Y LA VIOLENCIA DOMÉSTICA.}

Sin duda, los documentos europeos analizados en este libro (El CEDH y La Carta Social Europea) se habían quedado muy cortos en la definición y protección de la discriminación, centrada en la enumeración no jerárquica de factores o sistemas de exclusión, y en todo caso, centrada en lo laboral, como única esfera de lo social. Esa limitación ha hecho que muy recientemente, los Estados miembros del Consejo de Europa y demás signatarios firmaran el Convenio del Consejo de Europa sobre Prevención y Lucha contra la Violencia contra la Mujer y la Violencia Doméstica, hecho en Estambul el 11 de mayo de 2011.

El Preámbulo recuerda el Convenio para la Protección de los Derechos Humanos y de las Libertades Fundamentales (STE no 5, 1950), sus Protocolos, y la Carta Social Europea (STE no 35, 1961, revisada en 1996, STE no 163) arriba referida, entre otros. Pero no sólo se queda en éstos. No se olvida de las recomendaciones del Comité de Ministros a los Estados del Consejo de Europa, tales como la Recomendación Rec (2002)5 sobre la protección de las mujeres contra la violencia, Recomendación CM/Rec (2007) 17 sobre normas y mecanismos 
de igualdad entre las mujeres y los hombres. Y es que el Consejo Europeo es sabedor desde antaño (ya se recogía en los primeros informes originarios de la redacción del Protocolo no 12) y reconoce explícitamente "que la realización de iure y de facto de la igualdad entre mujeres y hombres es un elemento clave de la prevención de la violencia contra la mujer". Este reconocimiento le obliga, asimismo a partir de la naturaleza estructural de la violencia contra la mujer basada en el género y algo más: a admitir que la violencia contra la mujer es uno de los mecanismos sociales cruciales por los que se mantiene a las mujeres en una posición de subordinación con respecto a los hombres, y ello reatraviesa otros cruces sistémicos de discriminación ya sea por raza, religión, condición social, edad o discapacidad, entre otros. Efectivamente, la perspectiva interseccional de la discriminación obligaba a la revisión del Derecho antidiscriminatorio clásico, basado en la yuxtaposición de los factores de discriminación, como si todos ellos compitieran en peso y de manera excluyente, en lo que al goce de derechos y libertades se refiere. No nos olvidemos de las razones enumeradas por igual y sin orden jerárquico en el art. 14 del Convenio Europeo de derechos humanos y libertades fundamentales y reconfirmadas por el Protocolo $n^{\circ} 12$; a saber: razones de sexo, raza, color, lengua, religión, opiniones políticas u otras, origen nacional o social, pertenencia a una minoría nacional, fortuna, nacimiento o cualquier otra situación.

Sin embargo, entre estos sistemas o estructuras, hay uno que penetra en todos los demás. El factor sexogénero reatraviesa color (hombres negros v. mujeres negras); razas (hombres gitanos v. mujeres gitanas); religión (hombres musulmanes v. mujeres musulmanas; circuncisión v. infibulación); edad (hombres ancianos o niños v. mujeres ancianas o niñas); ubicación geográfica (hombre afganos v. mujeres afganas; hombres mejicanos v. mujeres mejicanas); discapacidad (hombres con discapacidad v. mujeres con discapacidad); orientación sexual (gays v. lesbianas)... que no podernos perder de vista. Hablamos de más del 52\% de la ciudadanía global compuesta por mujeres en su diversidad frente al $48 \%$ de hombres en su diversidad. No en vano, "(l)a historia de las luchas de la liberación de muchos grupos oprimidos por su etnia, su ubicación geográfica ( ... ) nos demuestra que partir de la eliminación de la discriminación contra esos grupos, es partir de la eliminación de la discriminación que sufren los hombres de esos grupos. Es decir, debido a que los hombres se perciben y son percibidos como el modelo de lo humano, también los hombres de los grupos marginados se perciben y son percibidos como el modelo del ser humano oprimido. Así, el negro que considera y es considerado el modelo del ser humano oprimido por su raza y, por ende, percibe la eliminación del racismo como la eliminación del racismo que vive él que no ella. Es así que si luchamos por la eliminación del racismo, o contra la opresión de clase o la discriminación de las personas con discapacidad o la homofobia, la experiencia nos ha demostrado que nuestra participación en esas luchas no nos garantiza que estaríamos eliminando a su vez el sexismo que sufren también las mujeres pertenecientes a etnias discriminadas, clases, pobres lesbianas, etc." (Facio, 1993, 17).

Esto implica ser conscientes de que las mujeres tienen necesidades e intereses que pueden o no coincidir 
con las de los varones, pero que en cualquier caso, son necesidades e intereses tan específicos a su sexo y humanidad, como los intereses y necesidades del sexo masculino son específicos a su sexo y humanidad. Y esto va más allá, sin duda del tradicional enfoque proteccionista otorgado por el Derecho discriminatorio clásico a la maternidad y al embarazo, y siempre desde el ámbito laboral, que opta por hacer "especiales por su vulnerabilidad biológica" a las mujeres, como sería el caso del enfoque de la Carta Social Europea (art. 8). Ello implicaría, entre otras cosas, admitir -si insistiéramos en el ámbito laboral- que la normativa que rige los contratos de trabajo son neutras en cuanto al sexo, pero que posee un sujeto implícito varón (patrón y medida del individuo) que excluye inexorablemente a las mujeres por no ocupar la plantilla de "lo humano". Este enfoque serviría, por supuesto, para aquellos países - practicantes de la discriminación indirecta- que se jactan de tener ciertas políticas proteccionistas para las mujeres, pero cuanto más para aquellos que, incluso en la actualidad, prohíben sin contemplaciones a las mujeres su presencia en el mundo laboral, sin el visto bueno del hombre. El Reporte sobre Mujeres, Negocios, y Derecho 2016, del Banco Mundia/ha puesto sobre la mesa que 19 de las economías analizadas requieren permiso de los maridos para que las mujeres puedan trabajar; a saber: Bathréin, Bolivia, Camerún, Chad, Congo, Gabón, Guinea, Irán, Jordania, Kuwait, Mauritania, Níger, Qatar, Sudán, Siria, Emiratos árabes Unidos, Cisjordania, Gaza y Yemen. La miscelánea y cruce de sistemas y estructuras excluyentes en este contexto no requieren de mayor comentario y la primacía de la subordinación estructural de género reatravesándolos tampoco.

Asimismo, la incorporación de la interseccionalidad al mainstreaming de género implica "reconocer que las políticas públicas de igualdad no pueden ignorar que las mujeres no configuran un grupo homogéneo (que tienen distinta orientación sexual, etnia, clase, religión, etc.), ni que históricamente, un determinado subgrupo de mujeres (blancas, de clase media-alta, occidentales, etc.) ha universalizado sus experiencias, intereses y necesidades en detrimento de los de muchos otros. (...) Sin embargo, la toma en consideración de la problemática de la interseccionalidad no puede hacer perder de vista la importancia específica del sistema sexo-género en las políticas (incluyendo las de igualdad). Dicho de otro modo, la interseccionalidad no debe servir para desmantelar el reconocimiento del sistema sexo-género como "corriente principal" en las mismas. Es más, la virtualidad del mainstreaming de género se apoya en buena medida en esto último, y no en la mera transversalidad" (Barrère Unzueta, 2010,251; Crenshaw, 1989).

Todo ello ha llevado, como hemos analizado anteriormente, a que desde los organismos internacionales se desplegara una normativa antidiscriminatoria específica, así como conferencias internacionales específicas, que dotaron y están dotando a las políticas públicas de igualdad de género de un papel principal a través del mainstreaming de género (Gil Ruiz, 2012, 30). Y ello no puede ser de otro modo, ya que pese a la interseccionalidad de factores, lo cierto es que el factor sexo-género reatraviesa a todos los demás, hasta el punto de constatar con la experiencia que, la mitad de la humanidad, como son las mujeres, aparecen subordiscriminadas 
(Barrère Unzueta, 2014) en todos los países y sociedades a escala mundial. Además, si bien es cierto que tanto los hombres como las mujeres han sufrido discriminaciones según clase, etnia, preferencia sexual, discapacidad, entre otras, también lo es que ningún hombre/varón ha sido discriminado a causa de su sexo, frente a la mujer que sí (Gil Ruiz, 2012, 28). No en vano dicho argumento se visualiza tras la definición de "violencia contra la mujer por razones de género" acuñada por el propio Consejo de Europa recientemente; a saber: "se entenderá toda violencia contra la mujer porque es una mujer o que afecte a las mujeres de manera desproporcionada" (art. 3.d del Convenio del Consejo de Europa sobre prevención y lucha contra la violencia contra la mujer y la violencia doméstica).

Este enfoque interseccional con la perspectiva de género como principal viene incluso previsto en la Observación General no 28, párrafo 3ㅜ, a la Igualdad de derechos entre hombres y mujeres del Comité de derechos humanos, encargado de supervisar el Pacto Internacional de derechos civiles y políticos. Los Estados deben conocer y tener en cuenta la confluencia de factores para saber cómo afecta a las mujeres de manera específica.

Por lo tanto, en lo que al Consejo de Europa se refiere, habrá que esperar al Convenio de Estambul para que abrace un concepto de discriminación más acorde con el arbitrado en los instrumentos internacionales vinculantes, ratificados por casi todos los países del globo terrestre y que él mismo reconoce en su Preámbulo; a saber: el Pacto Internacional de Derechos Civiles y Políticos (1966) arriba aludido, el Pacto Internacional de Derechos Económicos, Sociales y Culturales (1966), la Convención de la Naciones Unidas sobre la eliminación de todas las formas de discriminación contra la mujer (CEDCM, 1979) y su Protocolo facultativo (1999), así como la Recomendación general no 19 del Comité de la CEDCM sobre la violencia contra la mujer, la Convención de las Naciones Unidas sobre los derechos del niño (1989) y sus Protocolos facultativos (2000) y la Convención de las Naciones Unidas sobre los derechos de las personas discapacitadas (2006).

Partiendo de todos ellos, el Consejo de Europa reconoce que la violencia contra la mujer es una manifestación de desequilibrio histórico entre la mujer y el hombre que ha llevado a la dominación y a la discriminación de la mujer por el hombre, privando así a la mujer de su plena emancipación. Asimismo recoge en su artículo 3.c) el concepto de género, decisivo en la comprensión de la violencia contra las mujeres y relevante en tanto antes no lo teníamos recogido en un texto con valor normativo. Como reza el Preámbulo del Convenio de Estambul, y para que no haya ninguna duda interpretativa: "la naturaleza estructural de la violencia contra las mujeres está basada en género". La definición omnicomprensiva del artículo 3 en torno a la "violencia contra las mujeres por razones de género" supera con mucho la mal llamada violencia doméstica al referirse a las mujeres, incluyendo comportamientos de violencia contra las mujeres por razones de género en la vida pública o privada, en tanto atentado a su estatus de ciudadana. Por lo tanto, ya no hay lugar a reduccionismos injustificados a las hora 
de aplicar las normas jurídicas (Lousada Arochena, 2014, 45), ni debate en torno a que la Violencia de Género forma parte de la discriminación en sí misma. Es decir, la violencia no es exactamente una forma de discriminación sino que forma parte de la discriminación, entendiendo este último concepto desde la perspectiva del sistema sexo-género (que subordina a las mujeres) y no desde la bilateralidad o neutralidad de los sexos, ni tampoco reducido a lo laboral (como única parcela de lo social) (Barrère Unzueta, 2013, 33).

El enfoque prioritario del gender maintreaming queda, asimismo claro en su artículo 6:

"Las partes se comprometen a incluir un enfoque de género, en la aplicación, y la evaluación del impacto de las disposiciones del presente Convenio y a promover y aplicar de manera efectivas políticas de igualdad entre mujeres y hombres y el empoderamiento de las mujeres".

\section{UN EJEMPLO DE INTERSECCIONALIDAD DE FACTORES Y LA} TRANSVERSALIDAD DE LA DISCRIMINACIÓN DE GÉNERO INVISIBLE: EL ASUNTO MARÍA LUISA MUÑOZ DÍAZ V. ESPAÑA (SOLICITUD No 49151/07)

Uno de los asuntos en donde puede detectarse esta subordiscriminación latente del género, frente a otros sistemas o estructuras también excluyentes, es el Asunto María Luisa Muñoz (alias la Nena) versus España (solicitud no 49151/07), resuelto recientemente por el TEDH. El asunto, en torno a la denegación de la pensión de viudedad de una mujer gitana, casada por el rito religioso de esta etnia, giraba en torno a la violación del artículo 14 de la CEDH (prohibición de la discriminación), junto con el artículo 1 del Protocolo 1 (protección de la propiedad) de la Convención Europea de Derechos Humanos

En noviembre de 1971 la demandante contrae matrimonio con otro miembro de la comunidad gitana, a través del rito religioso propia de este grupo étnico. Fruto de esta relación nacen seis hijos, inscritos convenientemente en el Libro de Familia expedido por el Estado español. En 1986 se les concedió el estatus de Familia Numerosa. Posteriormente, en 2000 el padre de familia fallece, habiendo cotizado a la Seguridad Social durante más de 19 años. La demandante solicitó la oportuna pensión de viudedad, pero la Seguridad Social la deniega basándose en el hecho de que su matrimonio no estaba registrado en el Registro Civil. La solicitante apeló al Tribunal Laboral y, en el juicio celebrado del 30 de mayo de 2002, éste le reconoció el derecho, alegando que la decisión sostenida por la SS era discriminatoria y atentaba contra la identidad étnica de María Luisa Muñoz (Sentencia del 7 de noviembre de 2002).

Pero posteriores apelaciones a la sentencia, anulando el fallo del Tribunal Laboral -STSJ de Madridterminaron con el asunto en el TC quien, a través de un recurso de amparo interpuesto por la demandante, dictaminó el 16 de abril del 2007 en contra de la señora Muñoz, en tanto que había decidido no casarse de acuerdo con las formulas reconocidas por la ley y que estaban a disposición de cualquiera con independencia de 
su origen étnico. El Tribunal además señaló la importancia de limitar la pensión de viudedad a los matrimonios reconocidos, más aún en un contexto en que los recursos de la Seguridad Social son limitados y tienen que cubrir una amplia gama de necesidades. Uno de los miembros del Tribunal Constitucional emitió una opinión disidente.

Tras ser desestimada su demanda en el TC, "la Nena” optó por recurrir al Tribunal Europeo de Derechos Humanos, donde se le reconoció la violación de los derechos protegidos por el Convenio Europeo en el artículo 14, junto con el artículo 1 del Protocolo 1. El Tribunal subrayó la importancia de las creencias de la solicitante derivadas de pertenecer a la comunidad gitana, que tiene sus propios valores bien establecidos y enraizados en la sociedad española. Igualmente, el Tribunal tomó nota del consenso internacional emergente entre los Estados europeos reconociendo las necesidades especiales de las minorías y la obligación de proteger su seguridad, identidad y estilo de vida, salvaguardar sus intereses y preservar su diversidad cultural.

Sin embargo, lo que el Tribunal ni las partes barajaron, es justo lo que hay detrás de estos valores bien establecidos y enraizados en la sociedad, propias del estilo de vida de las minorías, en este caso, de la raza gitana. El problema no es que "la Nena" haya podido sufrir discriminación por razón de su raza, ni siquiera por su religión, sino que ésta la sufre dentro de la cultura de su etnia y que el Estado ha dado cobijo a normas (escritas o no) que sostienen la práctica subordiscriminatoria para las mujeres como es el matrimonio gitano (Barrère y Morondo, 2011). A María Luisa Muñoz se le impidió trabajar fuera de casa, se le obligó a contraer matrimonio según ciertos ritos que incluyen la prueba del "pañuelo" (como constatación de su virginidad o prueba de escarnio en caso de desfloramiento), y cuidar a su marido hasta el fin de sus días. "La Nena”, nunca mejor dicho, se debía a las normas heteroimpuestas y subordiscriminatorias de la comunidad gitana, aceptadas sin discusión por el Estado español. Ésta debería ser la razón por la que el TEDH debía haber resuelto a favor de la mujer para cobrar la pensión de viudedad, y no el motivo de discriminación racial o étnica, pertenencia a una minoría nacional, ni tan siquiera discriminación religiosa.

Sin duda, todos estos argumentos están detrás de los matrimonios forzosos, matrimonios infantiles, violencia relacionada con la dote, la lapidación de mujeres por violaciones de sus cuñados, crímenes de honor, inmolación de la viuda, -sati hindú-, escisión, infibulación u otra mutilación de la totalidad o parte de los labios mayores, labios menores o clítoris de una mujer, o el generocidio cuando se busca la exterminación de las mujeres, como la masacre de Montreal o los crímenes de la Ciudad Juárez .... entre, lamentablemente, un largo etcétera de manifestaciones primarias de violencias o discriminaciones contra la mujer por el hecho de ser, sencillamente, mujer. 


\title{
IN CONNECTION WITH ARTICLE 14 OF THE EUROPEAN COURT OF HUMAN RIGHTS: CONCEPT, JURISPRUDENCE AND NEW CHALLENGES OF (AND BEFORE) THE COUNCIL OF EUROPE.
}

\begin{abstract}
The Council of Europe, like other major International bodies, is aware that 'the realisation of de iure and de facto equality between women and men is a key element in the prevention of violence against women'. This recognition has forced the Council to revise the classic antidiscrimination law, based on the juxtaposition of discrimination factors -sex, race, colour, language, religion, political or other opinions, national or social origins, starting from the structural nature of the subordination of women as citizens using the primary focus of gender mainstreaming. This work analyses the development of certain European documents, such as the European Convention of Human Rights, The European Social Charter and the recently signed Convention of Istanbul, within the new framework of antisubordiscrimination law accepted by Europe. The article also refers to certain international Conventions and conferences that have had an influence on these developments.
\end{abstract}

Keywords: Antidiscrimination law, equality, discrimination, gender mainstreaming, Council of Europe

\section{BIBLIOGRAFÍA}

BARRÈRE UNZUETA, M.A., El Derecho Antidiscriminatorio y sus límites, Grijley, Colección Derechos \& Tribunales, Perú, 2014.

"La interseccionalidad como desafío al mainstreaming de género en las políticas públicas", RVA.P., nº 8788, 2010, pp. 225-252.

"El "acoso sexual": una mirada a sus orígenes y a su evolución en la Unión Europea", en GIL RUIZ, J.M. (Coord.), Acoso sexual y acoso por razón de sexo: actuación de las administraciones públicas y de las empresas, Consejo General del Poder Judicial, no 36 Justicia y Sociedad, Barcelona, 2013.

BARRÈRE, M.A. y MORONDO, M.D., "Subordiscriminación y discriminación interseccional: elementos para una Teoría del Derecho antidiscriminatorio”, Anales de la Cátedra Francisco Suárez, 45, 2011, pp. 15-42.

BESSON, S., "Gender Discrimination under EU and ECHR Law: Never Shall the Twain Meet?" Human Rights Law Review, 2008, 8, (4), pp. 647-682.

CELIS et al., “Rethinking women's substantive representation”, Representation, 44, (2), pp. 99-110.

COURTIS, C., "La aplicación de los Tratados Internacionales de derechos humanos por los Tribunales nacionales. El caso de los derechos de la mujer" en MONEREO, C. y MONEREO, J.L., Género y derechos fundamentales, Comares, Granada, 2010, pp. 767-802.

CRENSHAW, K, "Dermaginalizing the Intersection of Race and Sex: A Black Feminist Critique of Antidiscrimination Doctrine, Feminist Theory and Antiracist Politics", University of Chicago Legal Forum, 1989, pp. 67 yss.

FACIO, A., Cuando el Género suena, cambios trae. (Una metodología para el análisis de género del fenómeno 
legal), San José, CR, ILANUD, 1999.

GIL RUIZ, J.M., Los diferentes rostros de la Violencia de Género, Dykinson, 2007.

Las nuevas Técnicas Legislativas en España, Tirant lo Blanch, Valencia, 2012.

(Coord.), Acoso sexual y acoso por razón de sexo: actuación de las administraciones públicas y de las empresas, Consejo General del Poder Judicial, n 36 Justicia y Sociedad, Barcelona, 2013.

"Nuevos instrumentos vinculantes para una Ciencia de la Legislación renovada: impacto normativo y de género", en Anales de la Cátedra Francisco Suárez, no 47, 2013, pp. 15-42.

"La Violencia Institucional de Género", en Anales de la Cátedra Francisco Suárez, no 48, 2014, pp. 9-18.

LÉPINARD, E., "Identity without Politics: Framing the Parity Laws and Their Implementation in French Local Politics", Social Politics: International Studies in Gender, State and Society, 13, 1, 2006, pp. 30 y ss.

LOMBARDO, E. et al., The Discoursive Politics of Gender Equality, Routledge, Abingdon-Nueva York, 2009.

LOUSADA AROCHENA,J.F., "El informe sobre el impacto de género en la elaboración de la normativa”, La Ley, no 6092, 23 de septiembre de 2004, p. 3-6.

2014, pp. 31-49.

"El derecho fundamental a vivir sin violencia de género", Anales de la Cátedra Francisco Suárez, no 48,

MONEREO, C. y MONEREO, J.L., Género y derechos fundamentales, Comares, Granada, 2010.

MURGUIALDAY MARTÍNEZ, C, "Igualdad y empoderamiento de las mujeres, zavanzamos hacia una nueva frustración". Conferencia impartida en el Salón de Actos de la Delegación del Gobierno de la Junta de Andalucía en Córdoba, el 21 de mayo de 2009, a instancias del Instituto de Estudios Trasnacionales (INET).

RADACIC, I., "Gender Equality Jurisprudence of the European Court of Human Rights", The European Journal of International Law, vol. 19. № 4, EJIL, 2008.

REY MARTÍNEZ, F., "Comentario a los informes del Consejo de Estado sobre el impacto por razón de género", Teoría y realidad constitucional, $n^{\circ} 14,2^{\circ}$ semestre 2004, pp. 500-523.

RODRÍGUEZ-PIÑERO, M., "El informe sobre el impacto por razón de género en la elaboración de las disposiciones normativas", AEQUALITAS, no 15, julio-diciembre 2004, p. 36

RUBIO, A. (Coord.), Estudio sobre la aplicación de la L.O.3/2007, de 22 de marzo, para la Igualdad Efectiva de Mujeres y Hombres, CGPJ, Madrid, 2011.

RUBIO, A. \& GIL RUIZ, J.M., Dignidad e Igualdad en derechos. El acoso en el trabajo, Dykinson, Madrid, 2012.

SCHIEK, D. y CHEGE, V. (Eds.), European Union Non-Discrimination Law. Comparative perspectives on multidimensional equality law, Rouletdge-Cavendish, Abingdon, 2009.

WOMEN'S LINK WORLDWIDE, “La jurisprudencia en materia de igualdad y no discriminación: la aportación de los Tribunales Europeos", en RUBIO, A. (Coord.), Estudio sobre la aplicación de la L.O.3/2007, de 22 de marzo, para la Igualdad Efectiva de Mujeres y Hombres, CGPJ, Madrid, 2011, pp. 213-241. 
WOODWARD, A.E., "Too late for gender mainstreaming? Taking stock in Brussels”, Journal of European Social Policy, vol. 18, 3, 2008, pp. 289-302.

Trabalho enviado em 27 de fevereiro de 2017.

Aceito em 13 de abril de 2017. 